\title{
ForSEAdiscovery: la construcción naval y el comercio de la madera del siglo XVI al $\mathrm{XVIII}$
}

Ana Crespo Solana | Instituto de Historia, CSIC

URL de la contribución <www.iaph.es/revistaph/index.php/revistaph/article/view/4279>

\section{RESUMEN}

ForSEAdiscovery es un proyecto fuertemente interdisciplinar que relaciona la historia marítima de la Edad Moderna y la arqueología subacuática con las Ciencias de la Información Geográfica (SIG), con la Dendrocronología, así como con diversas técnicas analíticas sobre la procedencia de la madera, especialmente la datación por radiocarbono. Es el primer proyecto financiado por el programa Marie Curie de la Unión Europea (Programa PEOPLE) orientado a la investigación histórica-arqueológica de pecios ibéricos. Durante sus cuatro años de desarrollo primigenio el proyecto ha logrado situar el estudio histórico-arqueológico de la historia marítima en el centro de un discurso teórico-técnico que abre nuevas líneas de investigación interdisciplinar y sobre todo en la generación de new data. Es así un proyecto holístico que se espera sea continuado por una amplia red de discípulos, científicos y colaboradores de diversas disciplinas.

\section{Palabras clave}

Arqueología Subacuática | Ciencias de la Información Geográfica | Comercio | Construcción naval | Edad Moderna | Historia marítima | Madera | 


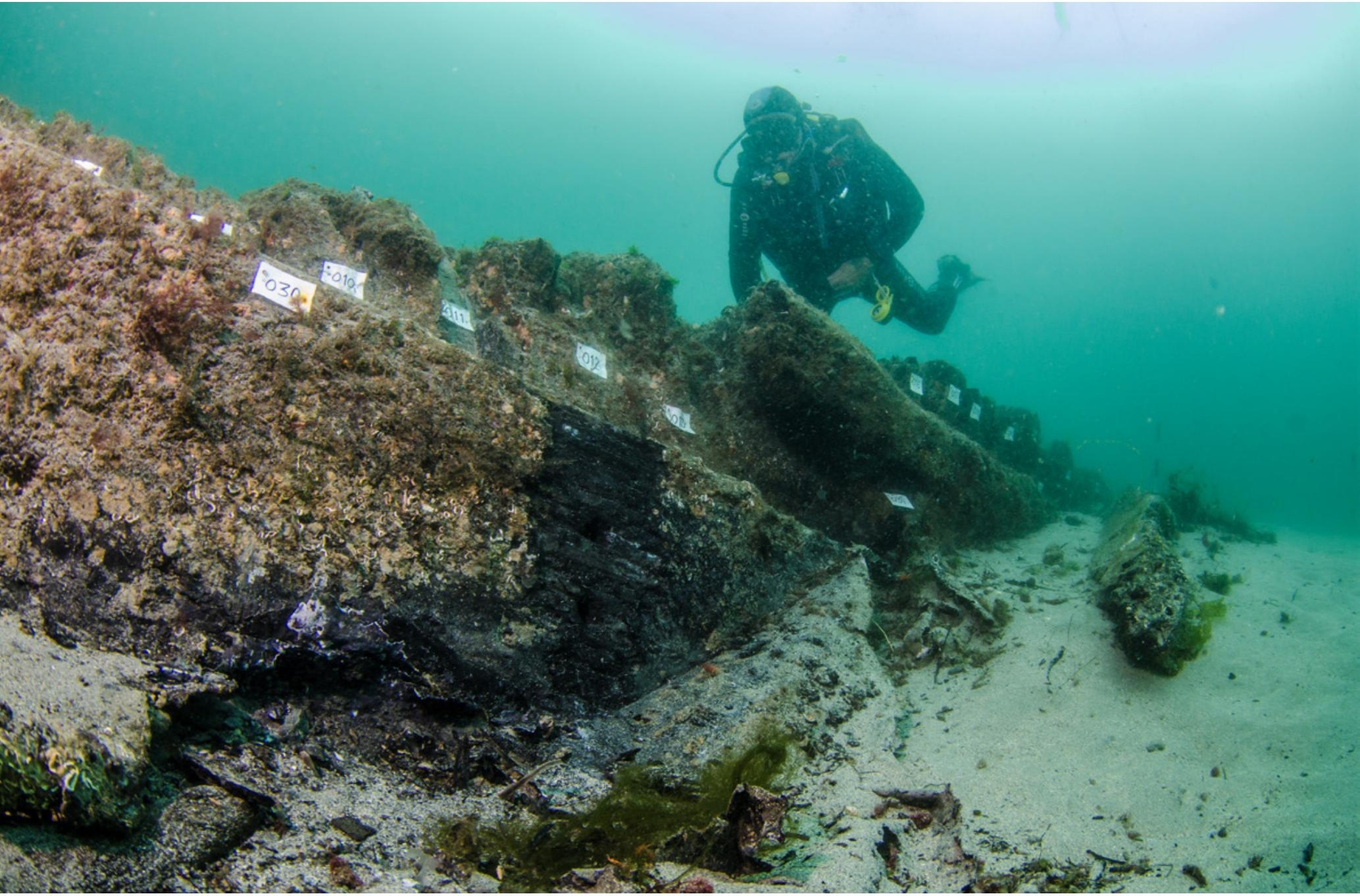

Galeón de Ribadeo: área de excavación (Junio de 2018) | foto MALTd, ForSEAdiscovery, Xunta de Galicia 
La investigación llevada a cabo y resultante de este proyecto ha sido financiada con fondos del People Programme (Marie Curie Actions) of the European Union's Seventh Framework Programme (FP72007-2013) under REA grant agreement no PITN-GA 2013-607545. Forest Resources for Iberian Empires: Ecology and Globalization in the Age of Discovery (16th18th centuries). Acronym: ForSEAdiscovery. Más información en <www.forseadiscovery. eu>
ForSEAdiscovery ${ }^{1}$ es un proyecto fuertemente interdisciplinar que relaciona la historia marítima de la Edad Moderna y la arqueología subacuática con las Ciencias de la Información Geográfica (SIG), con la dendrocronología, así como con diversas técnicas analíticas sobre la procedencia de la madera, especialmente la datación por radiocarbono. Es el primer proyecto financiado por el programa Marie Curie de la Unión Europea (Programa PEOPLE) orientado a la investigación histórica-arqueológica de pecios ibéricos. Durante sus cuatro años de desarrollo primigenio las investigaciones llevadas a cabo están procurando un mayor conocimiento sobre el origen y abastecimiento de la madera para la construcción naval, el análisis de las redes mercantiles que operaban en torno a este comercio, las políticas navales del período y su relación con la politización y canalización de los recursos forestales, así como su incidencia en la evolución de la arquitectura de barcos. Aparte de su planteamiento interdisciplinar y empírico que lo convierte en un proyecto único e innovador en el campo de las humanidades y las ciencias sociales, la conjunción metodológica logra situar el estudio histórico-arqueológico de la historia marítima en su verdadero contexto científico internacional, en el centro de un discurso teórico-técnico que abre nuevas líneas de investigación interdisciplinar y sobre todo en la generación de new data. Es así un proyecto holístico que parte de un amplio conocimiento histórico y que, esperemos, no solo será continuado por los miembros del Consorcio ForSEAdiscovery sino por una amplia red de discípulos, científicos y colaboradores de diversas disciplinas.

Un estado del arte actual sobre la economía, el medioambiente y el estudio de las actividades marítimas de España y Portugal durante los siglos XVI al XVIII aporta un estado de conocimientos historiográficos considerablemente amplio. Un capítulo menos señalado, o menos visible, ha sido la aplicación interdisciplinar de métodos dendroarqueológicos, especialmente en escenarios subacuáticos y marítimos, que facilite poder avanzar en los conocimientos sobre la procedencia de la madera que se utilizó para la construcción de barcos. Estos tipos de estudios han conocido interesantes aplicaciones en el campo de la arqueología subacuática española anteriormente pero casi siempre dedicado a pecios de época anterior al siglo XV, especialmente romanos y fenicios. Para épocas posteriores a las primeras décadas de la expansión ultramarina ibérica estos estudios deben ser, sin duda, contextualizados en un nuevo marco historiográfico que aporta novedosas asunciones primarias. En el contexto de la emergencia del capitalismo mercantil de la Edad Moderna, el comercio global de madera, el control de estos recursos y el desarrollo tecnológico eran aspectos inherentes al trasfondo ideológico de los imperios. Dos paradigmas claves surgen en esta investigación: en primer lugar, la evolución del navío ibérico, desde naos y galeones a fragatas y navíos mercantes con todas sus variantes. Esta cuestión resulta más problemática y, sin duda, urgente, dados los difíciles condicionantes a la hora de conocer un barco de la edad moderna bajo el agua. En segundo 
lugar, y considerado como un auténtico análisis de investigación multidisciplinar, una cuestión fundamental es la pregunta de cómo evolucionó tanto el comercio de madera como el uso que se llevó a cabo de estos recursos forestales. Ambos análisis son, sin duda, paralelos a los estudios sobre construcción naval ibérica que no pueden llevarse a cabo solo teniendo en cuenta la información histórica recogida en tratados de construcción y en archivos, dada la importante fuente de información que suponen los restos arqueológicos sumergidos, necesario además de confrontar con datos recogidos en archivos que hasta el momento han permanecido inéditos o menos valorados, y siempre desde una perspectiva histórica medioambiental y económica (CRESPO SOLANA, 2016).

En su esencia, el proyecto fue resultado de la conjunción de diversos esfuerzos individuales, que ya tuve oportunidad de explicar, reunidos en torno a un plan preliminar destinado a integrar estrategias para la configuración y establecimiento de una dendrocronología histórica de la Península Ibérica orientada además a establecer futuras línea de actuación en este campo. Se trataba del proyecto Filling in the blanks in European dendrochronology: building a multidisciplinary research network to assess Iberian wooden cultural heritage worldwide ${ }^{2}$. En poco tiempo ha sido posible presentar casos de uso interesantes sobre esta materia (SOBERÓN; PUJOL; LLERGO et ál., 2012: 411-422; DÓMÍNGUEZ-DELMÁS; NAYLING; LOUREIRO et ál., 2012: 118-136; DOMÍNGUEZ-DELMÁS; ALEJANO-MONGE; DAALEN et ál., 2015: 180-196); con especial mención del The Newport Ship Project, ejemplo paradigmático de la datación e identificación de madera de barcos gracias a la dendrocronología y que constituye la base metodológica de ForSEAdiscovery (NAYLING; JONES, 2014: 239-278; NAYLING; SUSPÉRREGUI, 2014: 279-291). Como valor añadido, las investigaciones a las que ha dado lugar el proyecto han sido prolíficas en cuanto que implican la realización de 10 tesis doctorales y 8 trabajos individuales de investigación, aparte de las diversas líneas aún pendientes y que están al cabo de salir a la luz en diversas publicaciones ${ }^{3}$. En estos trabajos se están culminando análisis con datos procedentes de archivos históricos y literatura sobre construcción naval, evidencias arqueológicas recogidas en prospecciones, muestreos de árboles vivos y madera de edificios históricos (para lo cual se han solicitado los permisos pertinentes) así como el análisis y catalogación de estas muestras en laboratorio. La dendroarqueología y otras técnicas para el estudio de la procedencia de la madera implican métodos utilizados para valorar la madera de los pecios que están siendo intervenidos y estudiados en las actividades científicas del proyecto. Esta disciplina permite datar las maderas arqueológicas para determinar el año en el que los árboles fueron talados, transportados y utilizados en la construcción de los barcos (NAYLING, 2008: 64-73). Ello supone un valor añadido al conocimiento histórico de estos pecios y permite validar la información extraída de fuentes documentales. En tres casos de uso en donde se han podido
2

Citado en: CRESPO SOLANA, A. (2016) ForSEAdiscovery: Génesis y marco histórico-metodológico de un Proyecto interdisciplinary en Humanidades. En VARELA GOMES, R.; VARELA GOMES, M. (coord.) A Gestâo dos Recursos Florestais Portugueses na construcâo naval da Idade Moderna: História e Arqueologia. Lisboa: IAP, pp. 1-15. Cf. SUSPÉRREGUI, J.; JANSMA, E. (2017) Towards A Better Chronology of Basque Heritage Using Time-Series from Renovation Waste. Tree-Ring Research, pp. 126-35. El proyecto duró entre 2009 y 2011 (Ref.: 236-61-001) dirigido por la profesora E. Jansma (Universiteit Utrecht) y Marta Domínguez-Delmás. Información sobre este proyecto en la web: $<$ https://www.nwo.nl/onderzoek-en-resultaten/ onderzoeksprojecten/i/17/5417.html>

3

Más información sobre las publicaciones en: http://forseadiscovery.eu/results/publications 
Toma de medidas sobre la construcción del buque por Arnaud Cazenave de la Roche | foto MALTd

ForSEAdiscovery, Xunta de Galicia

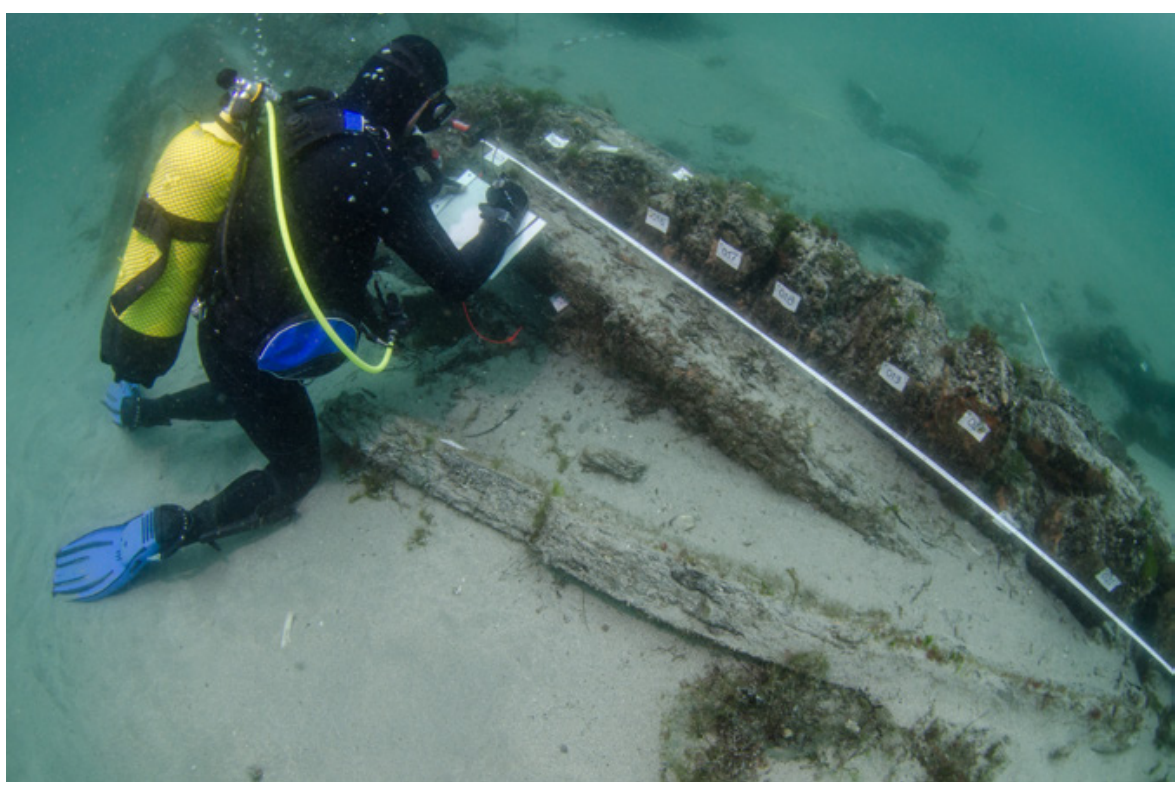

identificar los barcos (casos del Galeón de Ribadeo, la fragata Magdalena y el pecio de Belinho), gracias a una minuciosa investigación documental y dendroarqueológica, se demuestra la factibilidad de esta metodología (EGUILUZ MIRANDA; TRAPAGA MONCHET; DOMÍNGUEZ-DELMÁS, 2015; TRINDADE; DOMÍNGUEZ-DELMÁS; TRAORÉ, et ál., en prensa). Como valor adicional, este análisis se ha llevado a cabo de forma exitosa en otros trabajos y en tesis doctorales (CAZENAVE DE LA ROCHE, 2018). Además de los estudios histórico-arqueológicos, que luego comentaré someramente, tres ejemplos notables han sido las tesis doctorales de los ITN fellows, Fadi Hajj (HAJ, 2017), Marta Domínguez-Delmás (DOMÍNGUEZ-DELMÁS, 2015) y Mohamed Traoré (TRAORÉ, 2018). Como culminación se han logrado publicar dos importantes textos que reportan información valiosa sobre guías e instrucciones prácticas a la hora de seleccionar, muestrear y cortar madera de barcos sumergidos. En orden a poder extraer muestras válidas para el laboratorio es necesario implicar el trabajo de dendroarqueólogos en las etapas de selección de muestras bajo el agua (RICH; NAYLING; MOMBER at ál., 2017; DOMíNGUEZ-DELMÁS; RICH; DALY at ál., 2018).

Las técnicas de análisis sobre la procedencia de la madera suponen un auténtico código de barras útil para el entrecruzamiento, experimentación e integración de toda la información, siempre y cuando se proceda de acuerdo a un determinado protocolo de muestreo y extrayendo datos útiles que tras su depuración y procesamiento también pasan a formar parte de las dendrocronologías históricas así como de la propia base de datos del proyecto (The ForSEAdiscovery Database) que está sirviendo para realizar análisis entrecruzados de información (CRESPO SOLANA; CASTRO, 2016). Para que las 
muestras de madera sean factibles para la datación arqueológica es necesario que dichas muestras sean de una especie que produzca anillos con resolución anual, con una muestra con suficientes anillos (Tree-rings), y en un contexto geográfico en el cual se hayan establecido previas cronologías de referencia espacio-temporales (DOMíNGUEZ-DELMÁS, 2013: 1080-1094). Junto a la historia y la arqueología, estas técnicas se relacionan tanto desde el punto de vista teórico (en el planteamiento de las hipótesis primarias del proyecto y en su epistemología) como en el uso de diversas metodologías complementarias a la hora de dar respuesta a los problemas que se plantean en la propuesta de investigación. Estas disciplinas son también suplementarias a la hora de dar respuesta a las preguntas relacionadas con el dilema de si realmente los recursos forestales ibéricos pudieron mantener el aumento de la demanda de madera experimentado entre los siglos XV al XVIII o si fue ésta importada desde otras partes, como en muchos casos sí sucedió desde la perspectiva de las evidencias históricas y documentales, especialmente a partir de la denominada crisis de la Armada de 1580. Esta clásica teoría historiográfica ha condicionado tanto la propia historia marítima y naval ibérica como los estudios arqueológicos en pecios.

\section{EL MARCO HISTÓRICO-ARQUEOLÓGICO}

La justificación de la investigación se basa en que, durante los siglos de la Edad Moderna, denominados como la primera edad global (siglos XVI al $X V I I I)$, la construcción naval era una industria relacionada con el desarrollo de los imperios. Las técnicas de construcción naval evolucionaron y se perfeccionaron desde el punto de vista tecnológico, se mejoraron los barcos destinados a las exploraciones oceánicas, el diseño y aparejamiento de los buques de guerra y mercantes, así como la propia organización naval. Este desarrollo fue importante para los imperios ibéricos, pioneros en la construcción de ese mundo atlántico de interacciones políticas, culturales, económicas y sociales. Junto al escenario abierto por España y Portugal, la interacción socio-cultural, tecnológica y económica con otras naciones marítimas, especialmente con los maritime powers, Holanda e Inglaterra, supone la inclusión en este esquema de análisis de una perspectiva comparada y de análisis de transferencia de tecnología en un mundo mucho más conectado y entangled de lo que se ha señalado en estudios anteriores. Efectivamente, hubo más interferencia y traspaso de conocimientos tecnológicos y económicos gracias a la constante migración de mano de obra especializada en oficios relacionados con el comercio y el sector naval, tal como se demuestra en los estudios sobre arquitectura naval de las distintas épocas en diferentes localizaciones geográficas. De hecho, la transferencia de tecnología sobre construcción naval, las diferencias entre la teoría y la práctica comprobada en evidencias arqueológicas y la consideración de astilleros y arsenales como centros neurálgicos de experimentación, son temas aún pendientes en 
4

Entre estos trabajos destaco: QUINTERO GONZÁlEZ, J. (2000) El arsenal de la Carraca (1717-1736). Madrid: Ministerio de Defensa, Instituto de Historia y Cultura Naval, 2000; SERRANO ÁLVAREZ, J. M. (2018) E astillero de La Habana en el siglo XVIII. Historia y Construcción naval. Madrid: Ministerio de Defensa. Cf. ALBEROLA ROMÁ, A.; MAS GALVÁN, C.; DIE-MACULET, R. (ed.) (2015) Jorge Juan Santacilia en la España de la Ilustración. Alicante: Universidad de Alicante, Casa de Velázquez.

Han sido muy estudiados desde el punto de vista legal: MARTÍNEZ GONZÁLEZ, A. J. (2014) La Elaboración de la Ordenanza de Montes de Marina, de 31 de enero de 1748 base de la política oceánica de la Monarquía española durante el siglo XVIII. Anuario de Estudios Americanos, 71, 2 Sevilla, pp. 571 602. la investigación a pesar de los buenos estudios existentes sobre astilleros. No obstante, es en estos valiosos trabajos en donde se deduce este continuo trasvase de experimentación, transferencia de conocimientos y conocimiento científico, más estudiado para el siglo XVIII, como, por ejemplo, fue la doble influencia entre España e Inglaterra o el caso de la influencia francesa en Cuba. De entre estos trabajos es quizás la obra de Quintero González la que más ha profundizado en las cuestiones relativas a la madera de los barcos desde un punto de vista histórico ${ }^{4}$.

Como centro neurálgico de la investigación histórica-arqueológica se logra la elaboración de una narrativa espacio-temporal e interdisciplinar sobre la historia y evolución de los modelos navales de los imperios ibéricos en el contexto de la expansión marítima, la politización de los recursos forestales, sus causas y consecuencias medioambientales, y en la dinámica social y económica del comercio global de madera durante los siglos XVI al XVIII. Sobre estas cuestiones es posible extraer algunos resultados preliminares que hacen referencia a la relación entre la administración forestal y la reglamentación relativa a la construcción naval. Se han establecido también las características de las regiones originarias de las cuales se extrajo madera, no solamente de los "montes de marina" sino que se han incluido algunos Reales Sitios, así como otras áreas cercanas a emplazamientos marítimos costeros, montes y dehesas, sobre todo en Andalucía y en el País Vasco, centros importantes de construcción naval, en donde se ubicaban diversos astilleros y careneros. Uno de los trabajos más importantes del proyecto es una tesis doctoral en curso sobre el surtimiento de madera en Andalucía (TRINDADE, 2015: 57-65).

Además, se ha analizado también las diversas casuísticas de los aprovechamientos forestales en localizaciones administradas directamente por la Corona, como el denominado Soto de Roma (en Fuente Vaqueros, Granada), y en las regiones de Asturias, Cantabria, Galicia, o amplias zonas de Portugal (VARELA GOMES; TRAPAGA MONCHET, 2017; TRAPAGA MONCHET; SANTOS, 2015: 62-68). Unos datos recogidos sobre estos estudios espaciales permiten conocer la fuerte presión que sobre los bosques ibéricos tuvo tanto la Corona como las élites nobiliarias y eclesiásticas locales que intentaron organizar desde muy pronto una reorganización de los recursos forestales y en regiones que sobredimensionaban las áreas establecidas por las posteriores (y curiosamente tardías) reglamentaciones sobre los montes de marina y la creación de los Departamentos marítimos entre 1726 y $1748^{5}$. De hecho el control de los bosques y su relación con la marina es muy anterior tal como aparece reflejado en la Novísima Recopilación de las Leyes de España y en la constitución de la Superintendencia de montes y plantíos en 1574 y sus importantes antecedentes desde el siglo XV (LEYES, 1805-1829: vol. 6, pp. 193-194; cf. MARTÍNEZ GONZÁLEZ, 2015: 43 y ss.). 

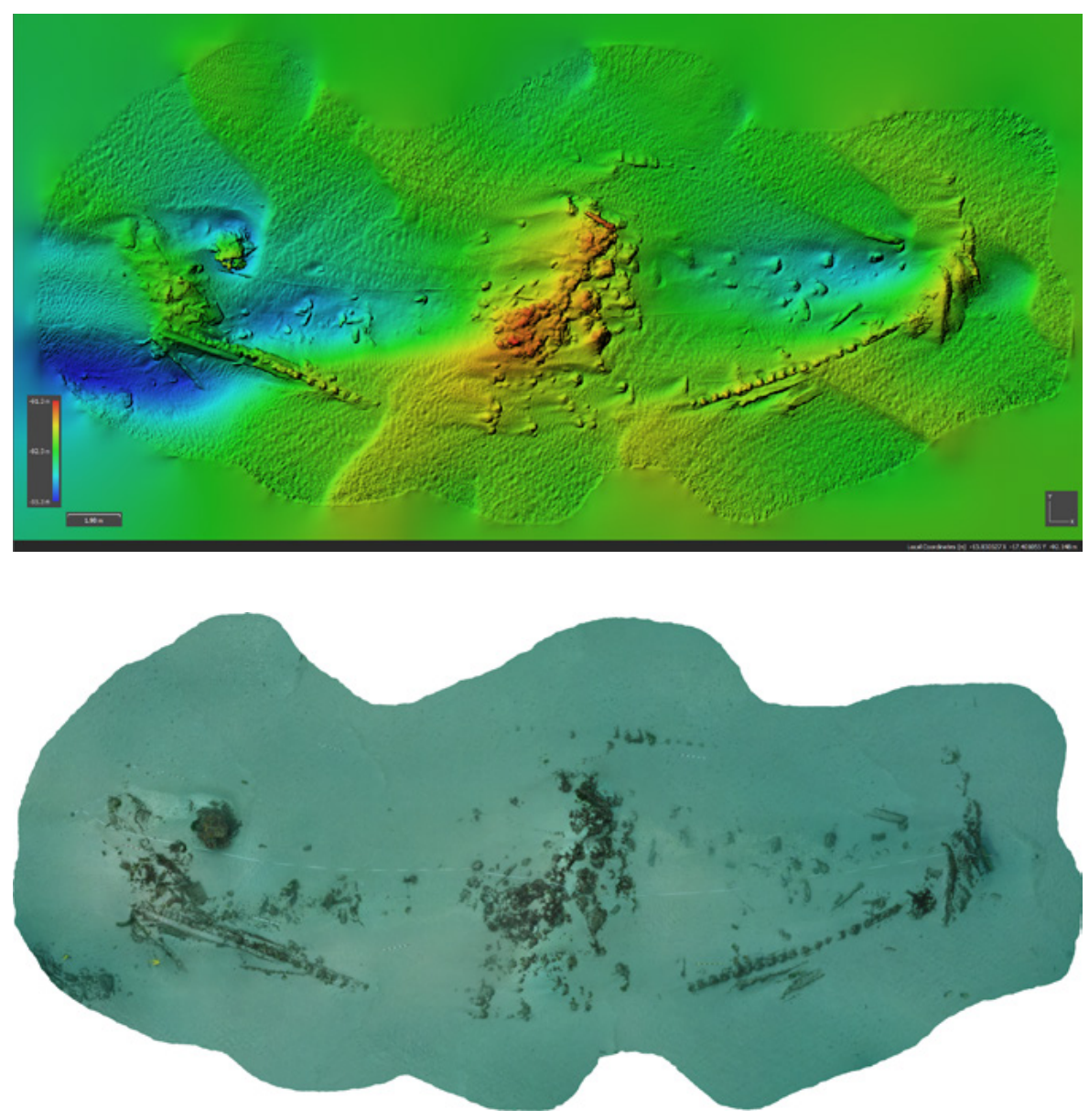

Screenshot Ribadeo I site | imagen Brandon Mason (MALTd, ForSEAdiscovery, Xunta de Galicia)

Desde el punto de vista económico y social, precisamente en los litorales de las costas europeas, se empezaron a desarrollar sociedades marítimas relacionadas con el comercio, las finanzas, las actividades portuarias y nuevos oficios vinculados a la expansión atlántica. Todo lo relacionado con la construcción naval estuvo también presente en dicho desarrollo socio-económico (CRESPO SOLANA, 2016: 3; 2017: 83-105). El establecimiento de nuevas rutas comerciales, el crecimiento demográfico y la migración coincidieron con el desarrollo de una industria integrada de artillería para la navegación marítima: navíos mercantes armados, galeones, flotas organizadas y pequeños barcos. El barco de la primera edad global, en sus modelos diferentes, constituía una tecnología puntera para la época que no solo influyó en el desarrollo de estas sociedades marítimas sino en las formas de canalizar recursos naturales. Estos procesos se desarrollaban en ciudades portuarias que de alguna u otra manera se empezaron a conectar con nuevos usos económicos y comerciales a partir del siglo XVI. Como coordinadora del proyecto de investigación, ya traté ampliamente tanto la historia naval 


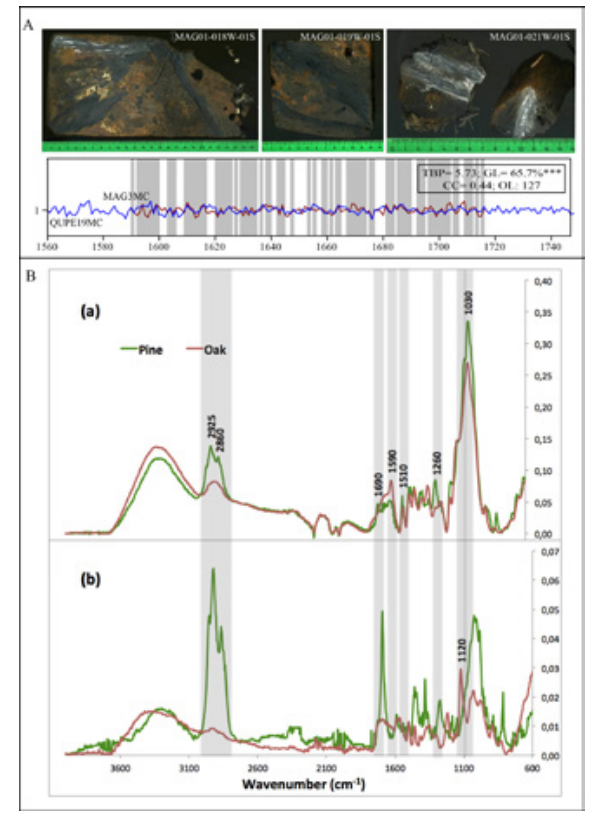

Equipo FTIR-ART Agilent Cary 630 FTIR Expectometro, equipado con "single-reflection diamond crystal" | fuente TRINDADE, DOMÍNGUEZ-DELMÁS, TRAORÉ et ál., en prensa

$$
6
$$

Un estado de la cuestión sobre estos problemas en: ALMAGRO-GORBEA, M (2008) La arqueología submarina hoy en España. En ALCALÁ-ZAMORA, J.; QUEIPO DE LLANO, J. (coord.) La España oceánica de los siglos modernos y el tesoro submarino español. Madrid: Real Academia de la Historia, 2008, pp. 11-47 como las redes mercantiles y su relación con la logística del comercio global que tuvo en la explotación de recursos naturales una de sus más importantes consecuencias (CRESPO SOLANA, 1996; 2001; 2014). Ambos temas se han tratado tanto desde el punto de vista comparado, empírico (con la creación de bases de datos y aplicación de SIG) y socio-económico, con especial hincapié en las rutas del comercio español de la Carrera de Indias y su relación con el mundo comercial del Golfo Caribe y el norte de Europa, básicamente Holanda y el Báltico. Gracias a la información contenida en la base de datos del Sound Toll Register online, ha sido posible desarrollar una investigación que destaca la importación de madera a la Península Ibérica, además de cotejar con otras fuentes de archivo, especialmente de la sección Tribunal Mayor de Cuentas, del Archivo General de Simancas, a partir de los cuales ha sido posible reconstruir unas series completas para los años comprendidos entre 1730 y 1770 con relación al Departamento de Cádiz (GALLAGHER, 2016: 752-773; CRESPO SOLANA, 2009; CRESPO SOLANA, 2018a: 77-94). Gracias a esta investigación se ha podido realizar un completo trabajo sobre la fragata de guerra del siglo XVIII Santa María Magdalena, construida en los astilleros de Estero en Ferrol (Galicia) en 1773 y hundida en 1810 en la bahía de Viveiro en el contexto de la Guerra de la Independencia (1808-1814) (TRINDADE; DOMÍNGUEZ-DELMÁS; TRAORÉ et ál., en prensa).

La historia naval y marítima española es muy amplia, pero con escasos estudios arqueológicos completos dedicados al análisis del diseño constructivo del barco ibérico de los siglos XVI al XVIII. Por lo que se puede observar de los trabajos existentes, y aunque en distintos contextos legislativos y administrativos, es un problema bastante generalizado en los países de la Unión Europea en la actualidad, al poseer un patrimonio sumergido enorme pero continuamente acosado por el expolio de los cazatesoros, como los ejemplos del Nuestra Señora de Atocha, el pecio de la Armada de Irlanda, La Girona, o los navíos de la flota de Manuel de Velasco de 1702 hundidos en la bahía de Rande, y, especialmente, el lamentable episodio que ha trascendido internacionalmente, el caso del pecio de Nuestra Señora de las Mercedes, que sin duda ha abierto un antes y un después en el campo de la arqueología subacuática española ${ }^{6}$. No obstante, existe una notable contraposición con los modelos de estudios sobre historia y arqueología marítima de la Edad Moderna que se tienen en el Reino Unido, Países Bajos o Portugal. Sin embargo, en el caso español existen trabajos importantes dedicados a galeones y navíos de las flotas españolas de los siglos modernos, que enlazan estos patrimonios sumergidos con una hermosa narrativa sobre el devenir de los naufragios históricos (PÉREZ-MALLAINA BUENO, 2015).

Recientemente destacan los trabajos realizados en el navío de línea El Triunfante, hundido en 1795 en la Bahía de Rosas, y que es uno de los pocos pecios de la Edad Moderna intervenidos en España, con un estudio histó- 
rico y arqueológico muy completo, que aporta información sobre los detalles constructivos, la arqueología de la batalla y la artillería (FUENTE DE PABLO, 2006; PUJOL I HAMELINK; VIVAR I LOMBARTE; FUENTE DE PABLO, 2011). Hormaechea, Rivera y Derqui mencionan en su obra, sobre los galeones españoles del siglo XVII, unos pocos yacimientos arqueológicos objeto de prospecciones arqueológicas de buques ibéricos (pecio de Cais de Sodre, en Lisboa; la nao vasca San Juan en Red Bay, o la nau Nossa Senhora dos Martires, el Pepper wreck, también en Lisboa) (HORMAECHEA; RIVERA; DERQUI, 2012; CASTRO; YAMAFUNE; EGINTON at ál., 2011: 328-34; LOEWEN, 1998: 193-199; CASTRO, 2005). A estos importantes trabajos se suman los trabajos de Carlos León Amores sobre la flota de azogue de 1724, los estudios de Miguel San Claudio sobre navíos de la Armada hundidos en Galicia, el Galeón de Gerona, hundido en 1654 (estudiado por Xavier Nieto) o el pecio Deltebre, de época algo más tardía (LEON AMORES, 2009: 178 y ss.; SAN CLAUDIO SANTA CRUZ; GONZÁLEZ GALLERO; CASABAN at ál., 2014: 169-178; MARTÍNEZ LILLO; BLANQUEZ, 1993: 163-169; VIVAR LOMBARTE; GELI; NIETO PRIETO et ál., 2014: 221-227); y el interesante caso del denominado Mercante San Sebastián, y otros pecios de la Edad Moderna estudiados por el Centro de Arqueología Subacuática de Cádiz (MARTÍ SOLANO, 2014: 109-118; GARCÍA RIVERA; MARTÍ SOLANO; ALONSO VILLALOBOS et ál., 1995: 105-124; RIDELLA; ALZAGA; ENRÍQUEZ MARCÍAS et ál., 2017: 11-65). En verdad, desde el punto de vista tecnológico e histórico, no hay nada más completo como los trabajos sobre los galeones del siglo XVII de Hormaechea, o de especialistas como Esteban Mira Caballos, Casado Soto o Serrano Mangas, por citar algunos relevantes, y que suponen una referencia del marco histórico fundamental para los anteriores trabajos arqueológicos (HORMAECHEA; RIVERA; DERQUI, 2012; MIRA CABALLOS, 2005; CASADO SOTO, 2009: 393-410; CASADO SOTO, 2003: 37-70; SERRANO MANGAS, 1989). En estas obras se han estudiado los barcos tal como aparecen descritos en las ordenanzas de principios de siglo XVII y aquellas variantes de los mismos hasta muy entrado el siglo XVII cuando en las últimas décadas empieza a emerger la figura única de Antonio Gaztañeta que entronca con las reformas del comercio y la armada de inicios del siglo XVIII y el comienzo de una nueva etapa de experimentación en la construcción de navíos. Políticas ilustradas en el siglo XVIII en materia de conservación forestal, cuando se produce un cambio sensible basado en la importancia dada a la demanda sobre la comercialización de la madera.

Además se ha valorado en varias ocasiones la teoría de la denominada transición ibérica (el trasvase arquitectónico evolutivo del barco mediterráneo al Atlántico), aún falta de comprobar bajo el mar con datos arqueológicos, y especialmente se ha analizado sobre la teoría los cambios y alteraciones en las medidas de las partes del barco y la razón de ello. No obstante, en un trabajo compilatorio, Carla Rhan Philips señalaba el enorme avance de 

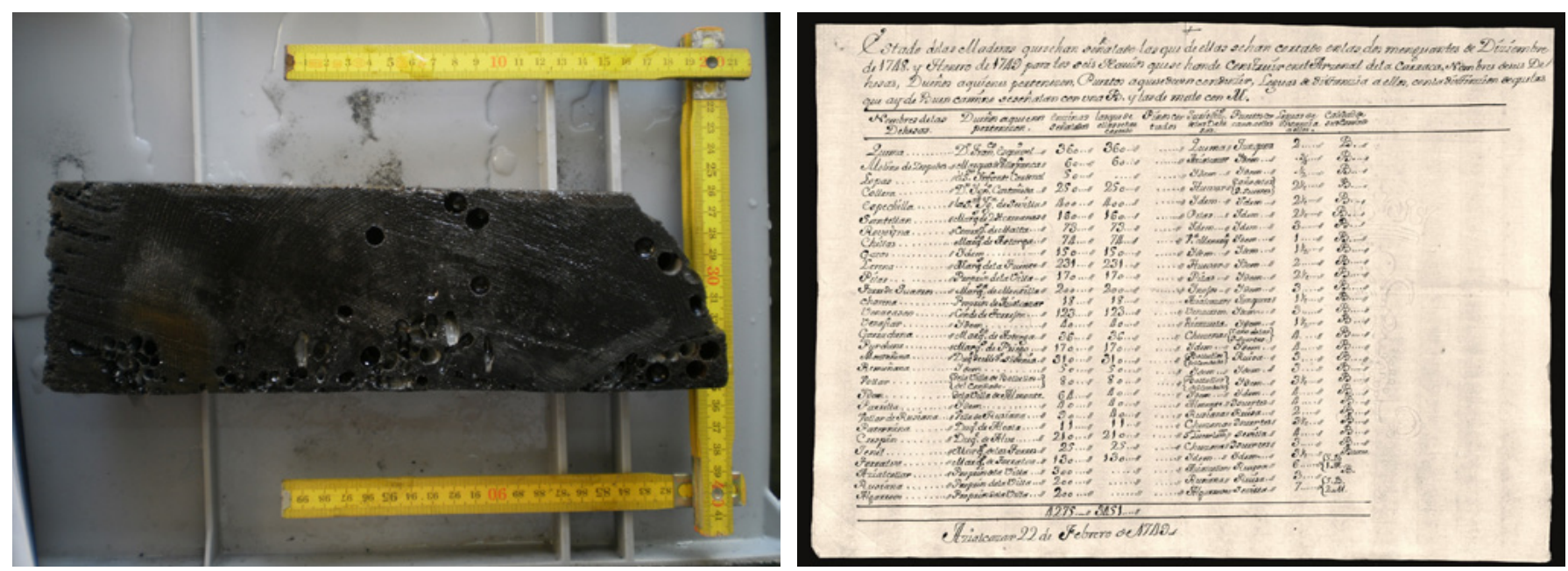

Muestras de tablas del casco de pino procedentes de La Magdalena, 18th c. Fragata española, Viveiro, Galicia | foto USC, ForSEAdiscovery

Documento del Archivo General de Simancas, Secretaría de Marina, Asientos, 608, "Estado de las Maderas que se han señalado las de que de ellas sen han cortado...", Aználcazar, 22 de Febrero de 1749 | foto Ana Rita Trindade, CSIC

la historia naval hispana en la que, sin embargo, apenas se ha contemplado la perspectiva de la madera como recurso natural de primera importancia para la industria, camuflada en la mayoría de los estudios como otro recurso más en el rico campo de los conocimientos sobre las batallas navales y la lucha por la hegemonía marítima (RAHN PHILIPS, 2013: 254-269). Algunas extraordinarias excepciones, especialmente para el siglo XVIII, han valorado su importancia desde diversos puntos de vista (BAUDOT MONROY, 2012: 297-328; QUINTERO GONZÁLEZ, 2004b: 81-94; 2004a: 27-40; 2004c); sin contar interesantes valoraciones para épocas anteriores como las que realiza Serrano Mangas, uno de los pioneros en señalar la relación entre importación de madera a Andalucía, explotación y construcción naval en un contexto bélico, como fue la Guerra de los 80 años, que incrementó la demanda peninsular y el papel holandés en el comercio de pertrechos. Hay que señalar que fue Alcalá-Zamora y Queipo de Llano el primero en percatarse de la dependencia que la construcción naval en astilleros y la importación de materiales tenía en las fases de las guerras de la Monarquía Hispánica en el norte de Europa, sobre todo en Flandes (SERRANO MANGAS, 1989: 102107; ALCALÁ-ZAMORA Y QUEIPO DE LLANO, 2001).

No obstante, el papel de la madera se ha estudiado más desde la ingeniería forestal y la ecología, aunque incluyendo el problema de la deforestación histórica relacionada con otros problemas económicos como la ganadería o su uso como carburante energético (URTEAGA, 1991: 17-43). Especialmente en el siglo XVIII se establecieron unas pautas administrativas forestales encaminadas a dos cuestiones principales, por un lado, una política coactiva de plantíos para remediar la escases de oferta forzando a los pueblos a la repoblación forestal; y la regulación de la demanda limitando las talas e intervención y control estatal sobre producción y precios. Su relación con la política naval puede detallarse a lo largo de la enorme producción llevada 
a cabo por los pensadores político-económicos del período ilustrado, como fue el estadista Gerónimo de Uztáriz, en su Theoria y práctica del comercio y marina, quien dedica un capítulo, poco conocido (el LXIII), a "las grandes utilidades que a los armamentos marítimos y navíos del comercio se siguen de haber establecido dentro de España, así el corte y conducción de árboles, tablazón y otras maderas para mástiles y demás obras de ellos, como la Fábrica de brea, alquitrán y jarcias" (UZTÁRIZ, 1724).

Relacionado con ello es importante conocer cómo se organizaron las redes de comercio de madera desde las áreas de producción. Historiográficamente se ha analizado la importancia de los recursos necesarios para la política naval teniendo en cuenta la evolución del capitalismo mercantil y los procesos de centralización y formación del Estado versus la dinámica de los negocios privados llevados a cabo por asentistas y constructores (VALDEZ-BUBNOV, 2018: 105-125; TORRES SÁNCHEZ, 2013: 159-199). Pero el principal problema planteado en el proyecto hace referencia a los diferentes orígenes de la madera localizada en pecios y la gran cantidad de información disponible en bases de datos históricas sobre cómo se transportaba la madera desde el norte y este de Europa a la Península Ibérica entre los siglos XVI al XVIII, algo que sin duda está relacionado con la especulación que en la propia época se tenía sobre los recursos forestales. En verdad, bosques e imperio son aspectos que se reflejan en el trasfondo económico y medioambiental de esta narrativa histórica, además de los fenómenos de comercio, migración de mano de obra así como la transferencia de tecnología, todo ello claves para comprender la evolución de la construcción del barco ibérico y el uso de la madera. Desde una época aún no definida de acuerdo a los datos históricos, el denominado "borne" de Flandes llegaba a los puertos españoles, especialmente andaluces, importados por las comunidades neerlandesas (flamencos y holandeses) asentadas en Sevilla y otros puertos marítimos. Un dato histórico lo da, como ejemplo, Mira Caballos, en un documento de 1652 sobre el reparo del órgano de una iglesia en Carmona: "Primeramente, con condición que de reparar y hacer sus fuelles de tablillas de madera de borne sazonados, dobles los valdreses y guarnecidos con sus cajas enlazados de madera de borne con las tablas principales de borne y los de debajo de pino de Flandes con sus cajas en que entren las pesas que han de ser de plomo"7. Esa era la razón de su nombre, borne de Flandes, aunque en verdad se refería a árboles de la familia de las Fagáceas (roble, Quercus spp), común en Europa del norte y occidental (Escandinavia, norte de Alemania, Holanda, Rusia y norte de España). Era su uso habitual tanto en el arte policromado, como en la construcción de edificios y barcos sin que hasta el momento no haya una cronología que lo defina aunque sí muchos trabajos además de otras investigaciones sobre los Pinus spp que constituían también un material muy utilizado (RODRÍGUEZ TROBAJO, 2008: 33-53). Las redes de los mercaderes flamencos de Sevilla eran solo una, pero importante y singular, ejemplo de la importación de madera para múltiples usos, pero sobre
7

Citado en MIRA CABALLOS, E. (1999) Carmona en la Edad moderna. Religiosidad y arte, población y emigración a América. Sevilla: Muñoz Moya editor, 1999, p. 218. Cf. DOMÍNGUEZ-DELMÁS, M.; VAN DEN BERSELAAR, H. (2009) Nederlands' hout op drift. Over houthandelsroutes en de herkomst van hout van de Late Middeleeuwen tot in de 18de eeuw ('Dutch' wood adrift: Timber trade and provenance of wood from the late Middle Ages until the 18th century). VITRUVIUS, n. ${ }^{\circ}$ 6, pp. 12-18 
8

Existen estudios de bosques desde la perspectiva histórica, como: ARAGÓN RUANO, Á. (2001) El bosque guipuzcoano en la Edad Moderna: aprovechamiento, ordenamiento legal y conflictividad. Donostia: Sociedad de Ciencias Aranzadi; REY CASTELAO, O. (1995) Montes y política forestal en la Galicia del Antiguo Régimen. Santiago de Compostela: Universidade de Santiago de Compostela. todo eran el reflejo de las complejas redes de agentes que actuaban detrás de la canalización de recursos forestales. Especialmente durante la dominación Habsburgo en Europa, y asentado durante la Unión de las coronas de Portugal y Castilla (1580-1640), la madera entró en un proceso dinámico y evolutivo de control, monopolización, almacenamiento, transporte y distribución por parte de las elites financieras relacionadas fuertemente con los círculos del imperio. Durante los siglos XVI y XVII los recursos madereros y la construcción naval llegaron a politizarse y reglamentarse en una paradoja medioambiental que podría definirse como "proteger es expoliar". Estas políticas se unieron a los designios navales especialmente durante la centralización administrativa de la época Borbónica en un auténtico negocio de estado militar y naval que ha sido ampliamente estudiado aunque escasamente desde el punto de vista de la madera como recurso (BAUDOT MONROY, 2012; REICHERT, 2016). No obstante, las cuestiones forestales y el poder marítimo se convirtieron en dos cuestiones ligadas, que crearon tensiones geopolíticas y alianzas, reflejadas a veces en los tratados de la época, en las leyes, en los reglamentos forestales y en la emergencia de nuevas actitudes para la gestión de los recursos naturales. Estas dos últimas cuestiones se han podido apreciar en la evolución de la Superintendencia de Montes y plantíos entre 1574 y 1748 (MARTíNEZ GONZÁLEZ, 2015). Se ha prestado atención a la organización de las pinadas en localizaciones regionales y a las importaciones de madera desde el Báltico (KUMAR, 2018a: 1-19; 2018b: 129-157; LÓPEZ ARANDIA, 2018: 127-168). Aún contado con estas valiosas investigaciones sobre la relación existente entre construcción naval, organización de recursos forestales y comercio de madera, aún quedan por conocerse más detalles sobre algunas cuestiones importantes: cómo se explotó y cómo se comercializó, especialmente a través de los agentes. De hecho, el análisis de las redes de mercaderes es el trasfondo principal del negocio de la madera, el interés de control por parte de las administraciones y es también uno de los temas de investigación del proyecto que ha producido varios trabajos individuales (alguno ya publicado) y dos tesis doctorales en vías de finalización, con especial mención del trabajo de Germán Jiménez Montes (GASCH-TOMAS; TRAPAGA MONCHET; TRINDADE, 2017: 187192; JIMÉNEZ MONTES, 2016: 693-702).

Hay que señalar una cuestión, escasamente considerada hasta ahora, es que en estos nuevos escenarios tecnológicos, sociales y económicos, hubo una presión y una demanda sin precedentes tanto sobre los bosques ibéricos como sobre otras zonas de Europa para el suministro de la madera adecuada para la construcción naval. Algunos trabajos son análisis regionales que ofrecen una rica información sobre la deforestación debida a problemas rurales y las políticas de repoblación forestal destinada a la construcción naval, como sucedió en Galicia ${ }^{8}$. Esta madera era en su mayoría roble (Quercus spp.) y pino (Pinus spp.), pero durante el proyecto ForSEAdiscovery se ha descubierto la importancia que otras especies tenían en la Península 
Ibérica para la provisión naval. Y su demanda llevó a que se crearan presiones para el abastecimiento de estos recursos y el desarrollo de nuevas redes de comercio de madera en el que estaban involucrados miembros de las redes y elites conectados con los intereses dinásticos y los centros de poder del imperio en Europa y en América.

Las cuestiones forestales y el poder marítimo se convirtieron en dos cuestiones ligadas, que crearon tensiones geopolíticas y alianzas, reflejadas a veces en los tratados de la época, en las leyes, en los reglamentos forestales y en la emergencia de nuevas actitudes para la gestión de los recursos naturales. Puede incluso llegar a decirse que durante este período la madera se convirtió en algo tan importante estratégicamente como el petróleo lo iba a ser en los siglos XX y XXI. En este contexto histórico y metodológico, el proyecto plantea una serie de preguntas que tratan de ser respondidas gracias a la relación entre el análisis de las rutas marítimas, las redes mercantiles relacionadas con el comercio global de la madera, la extracción de madera de pecios y muestreos en edificios históricos (con el fin de sustituir la escasez de árboles vivos residentes en los bosques ibéricos en la actualidad) y el análisis de la procedencia de la madera. Estas preguntas refieren si los recursos forestales ibéricos podían mantener este aumento de la demanda de madera o fue la madera importada desde otras partes. Si fue así, ¿cómo se organizaron las redes de comercio de madera desde las áreas de producción? La escasez de materias primas, ¿hizo que se alentaran los cambios tecnológicos que se produjeron en la construcción naval en el siglo XVI, o fueron estos resultados del intercambio socio-tecnológico entre el Mediterráneo y las tradiciones de construcción naval del Atlántico? ¿Dio lugar la demanda de madera a cambios sostenibles en las prácticas forestales en la Península Ibérica, o a la deforestación y al aumento de la dependencia de la importación?

\section{LA ESTRUCTURA ADMINISTRATIVA DEL PROYECTO}

El proyecto ITN (Initial Training Network) ha sido diseñado en seis programas de trabajo o Work Packages (WP). Tres de ellos están dedicados a investigación: WP1, Historical wood supply and dynamic trade networks; WP2, Nautical archaeology and shipbuilding; WP3, Wood provenancing. Los otros tres se han dedicado a gestionar la organización interna de la ITN: training activities (WP4), project management (WP5) y Dissemination and outreach activities (WP6), cuya responsabilidad cae sobre la coordinadora (Ana Crespo Solana) y dos de los miembros del consorcio (Nigel Nayling e Ignacio García González). Hay que subrayar que un buen management en la organización y dirección de un equipo formado por 15 investigadores seniors y 18 investigadores fellows contratados está en la base de poder acceder a las fuentes de financiación que ofrecen los programas europeos ${ }^{9}$.

9

Más información sobre el Consorcio ForSEAdiscovery en: http://forseadiscovery.eu/itn-supervisory-board 
https://forseadiscovery.wordpress.com/category/nautical-archaeology/; y algunas de las intervenciones en prensa: http://forseadiscovery.eu/news

\section{1}

Información sobre los investigadores fellows; http://forseadiscovery.eu/itn-fellows
Todos los WPs han estado fuertemente relacionados entre sí y sus componentes han colaborado mucho entre ellos, en la organización de campañas, organización de seminarios, conferencias y talleres (Network meeting) así como en actividades de dissemination (divulgación) del proyecto. Las actividades de divulgación se han llevado a cabo en muchos foros y ambientes, en la prensa, radio y televisión; y en la web del proyecto y en su blog ${ }^{10}$. La investigación está supervisada y en parte realizada y dirigida por un consorcio formado por 10 investigadores principales (PI) de 5 países y 9 instituciones y centros de investigación; así como 5 Associated partners (o socios) de Estados Unidos, Dinamarca, España, Polonia y Suecia.

Un total de 18 fellows, 15 de ellos Early Stage Researcher (ESR) y 3 Experienced Researcher, contratados de acuerdo a las exigencias del programa $^{11}$, han llevado a cabo proyectos individuales de investigación con diversos resultados, incluida la realización de 6 tesis doctorales, 4 (a fecha de esta publicación) ya presentadas en las correspondientes universidades. Además, los jóvenes investigadores han participado en todas las actividades del proyecto, incluyendo campañas, organización de eventos y seminarios.

A nivel general, los objetivos generales del programa Initial Training Network (ITN) son la formación para la investigación multidisciplinar y el aumento de la experiencia de los alumnos en las diferentes áreas de investigación con el fin de que puedan desarrollar habilidades transferibles para futuras carreras o profesiones en el mundo académico o en el sector privado. Además, se pretende la promoción de determinados campos de investigación gracias a la integración de herramientas, el conocimiento de metodologías que pue-

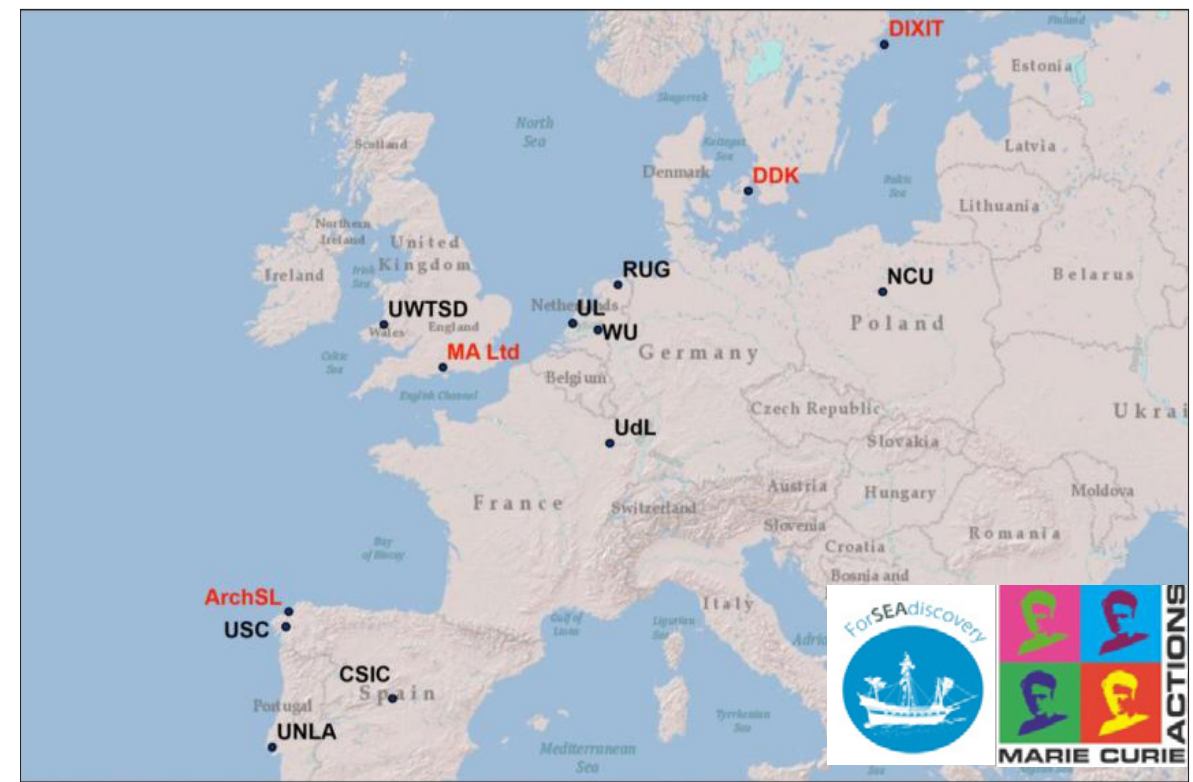


dan utilizarse de forma interdisciplinar, el desarrollo de conjuntos de datos de referencia en bases de datos que sean de open source, o acceso abierto, en la web. En definitiva, una integración de la investigación interdisciplinar. En el programa de trabajo ForSEAdiscovery esto se ha logrado mediante: primero, la participación de los becarios contratados en los cursos y talleres de capacitación destinados a desarrollar sus capacidades científicas, comunicación, gestión y liderazgo; y en segundo lugar, en la aplicación recíproca de técnicas metodológicas de las ciencias históricas, arqueológicas y las técnicas de análisis geo-químicos sobre la procedencia de la madera a diferentes casos de uso sobre el estudio de la historia de la explotación de los recursos forestales y su uso en la construcción naval durante diferentes estadios álgidos de la expansión marítima. El resultado, como se ha indicado, se ha reflejado en diversas publicaciones y trabajos de investigación en curso y una ingente profusión de datos compartidos de forma interdisciplinar en la base de datos ForSEAdiscovery. Precisamente, esto último ha producido una formación integrada y prolífica gracias al uso de los Sistemas de información geográfica (SIG), bases de datos y conocimientos de técnicas paralelas, como los Social Networks Analysis (SNA) o herramientas de análisis de redes, de acuerdo a una metodología establecida (CRESPO SOLANA, 2013). La base de datos, el SIG y la web mapping (o visualizador cartográfico resultante) tiene como objetivo integrar y visualizar las diferentes capas de información que se obtienen de las distintas disciplinas, permitiendo el estudio de la utilización histórica de los recursos forestales ibéricos, y la interacción entre las diferentes redes del comercio de madera en Europa. En el proyecto ForSEAdiscovery el modelo de datos orientado a SIG (que se explicará más adelante) se ha desarrollado a partir de un prototipo existente creado por mí, como coordinadora del proyecto, en anteriores proyectos $^{12}$. El contenido de los datos ha sido implementado con datos durante otro proyecto financiado por el Plan Nacional de Investigación I+D13. La base de datos y SIG ForSEAdiscovery está sirviendo como plataforma de manejo de datos para la investigación y los fellows se han iniciado con estas bases de datos en el conocimiento de la aplicación de los SIGs a las distintas disciplinas del programa.

\section{BREVE EXPOSICIÓN DE RESULTADOS}

El proyecto ForSEAdiscovery ofrece ya sus primeros resultados. De forma breve serán sumariados a continuación, aunque desarrollaré en un epígrafe aparte solo algunas cuestiones sobre la base de datos, como herramienta de integración para el análisis de resultados. En respuesta a las preguntas y problemas de investigación se han producido diversos trabajos interdisciplinares que arrojan algunas luces sobre conocimientos previos, así como generar datos inéditos. De acuerdo a las directivas del proyecto algunos de estos conjuntos de datos se están, o estarán en breve, dándose a conocer
12

Se trató del proyecto DynCoopNet, y cuya base de datos está localizada en el repositorio digital del CSIC. (Ref. EUROCORES,TECTESF project FP-004/DynCoopNet, 20052010).

13

Es el proyecto GlobalNet HAR2011-27694. Cf. CRESPO SOLANA, 2014: 2-44. 
http://forseadiscovery.eu/content/deliverables

15

Puede consultarse la información relativa en http://forseadiscovery.eu/content/maritimecampaigns

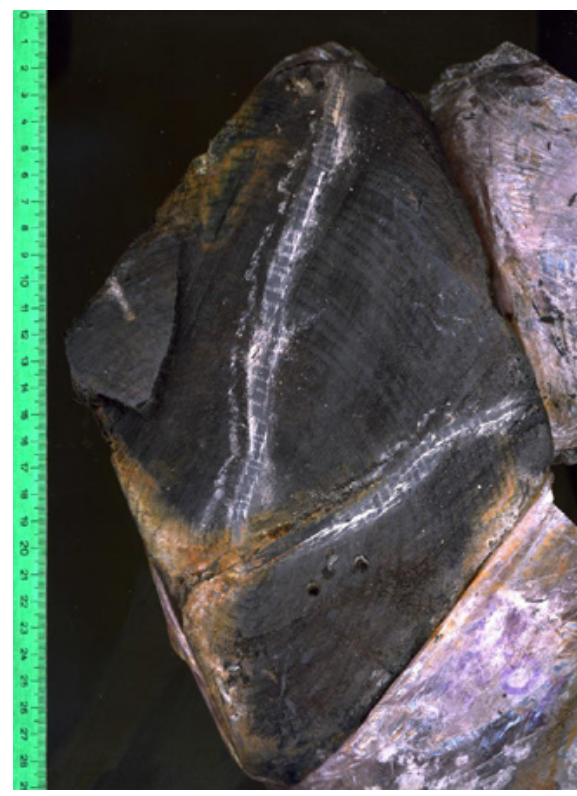

Yarmouth Road Wreck. Muestras del pecio recogidas durante la campaña del año 2015 para el análisis dendrocronológico e identificación de la madera | foto MALTd, ForSEAdiscovery en forma de deliverables, tal como quedaba estipulado en nuestro Annex 1, documento de trabajo incluido en el Grant Agreement. Estos resultados aparecerán en breve en la web del proyecto $^{14}$, y ofrecen, entre otras herramientas, un inventario exhaustivo de las fuentes históricas y geográficas sobre los suministros de madera (siglos XVI-XVIII). Este inventario sirve de base para el conocimiento sobre las fuentes de especies arbóreas, especialmente roble y pino utilizados para la construcción naval en el Atlántico ibérico durante la era de los descubrimientos y la expansión europea. Además, se dispone de un amplio catálogo de literatura y datos de archivos históricos. Una detallada información sobre los diferentes procesos de adquisición de la madera, su selección, comercio y transporte, son el objetivo de una tesis doctoral en curso llevada a cabo por Ana Rita Trindade que aporta un valioso e inédito SIG sobre las áreas de aprovisionamiento forestal.

Por último, un detallado estudio sobre las prácticas de gestión y las leyes específicas promulgadas para sostener y proteger los recursos forestales aspiran a completar los conocimientos actuales. Aparte de toda esta conjunción de datos que el proyecto ForSEAdiscovery deja en herencia a los seguidores de esta línea de investigación, el grueso de las actividades más importantes se basa, sin duda, en la organización de un modelo de datos orientado a SIG con información histórica, arqueológica y dendrocronológica de barcos y naufragios históricos. En segundo lugar, el modelo de trabajo llevado a cabo en campañas de arqueología subacuática y el establecimiento de unas dendrocronologías que, aunque hasta el momento son solo parciales y no abarcan todo el panorama geográfico de la Península Ibérica, suponen un verdadero motor para futuras aplicaciones en la datación de madera de pecios. Dentro del proyecto se han organizado varias campañas de arqueología subacuáticas en torno de hasta un total de cinco sitios arqueológicos en España: Finisterra/Costa da Morte, Ribadeo, la Fragata Magdalena y el pecio conocido como La Bayonnesa. En Portugal se ha organizado una campaña en cooperación con el proyecto coordinado por la Universidade Nova de Lisboa y la Cámara Municipal de Esposende en el denominado pecio de Belinho ${ }^{15}$. En breve saldrán a la luz nuevas publicaciones sobre cada una de estas intervenciones, aunque algunos de los resultados han sido ya divulgados ampliamente, incluso con la realización de la tesis doctoral de Miguel San Claudio (SAN CLAUDIO, 2017). Estos pecios fueron ya objeto de estudio anteriormente, e incluso de expolio o destrucción, como fue el caso de la fragata Magdalena. Los métodos llevados a cabo por nuestro equipo se orientaron al buceo en los sitios arqueológicos con objeto de establecer un registro y extraer muestras de madera. Uno de estos pecios, la corbeta de guerra francesa Bayonnaise posee abundante madera estructural en conexión. El pecio de la fragata de la Armada española Santa María Magdalena es uno de los ejemplos más interesantes, al conocerse su identidad, para la reconstrucción de sus características dendroarqueológicas (TRINDADE; DOMíNGUEZ-DELMÁS; TRAORÉ at ál., en prensa). Además se han reali- 
zado dos temporadas de excavaciones en un barco ibérico en Reino Unido, el Yarmouth Road wreck, hundido en el Solent cerca de la costa de la Isla de Wight (WATSON; GALE,1990: 183-192). Se trata de una carraca española, quizás nombrada Santa Lucía, que se perdió en la zona alrededor de 156716. El Pecio de Ribadeo, o Galeón de Ribadeo, es quizás la flag ship del proyecto ForSEAdiscovery que ha coordinado y participado en dos intervenciones. Este pecio, un galeón del siglo XVI, presenta características excepcionales y al momento están siendo objeto de estudio tanto su estructura arquitectónica como su madera (SAN CLAUDIO SANTA CRUZ; GONZÁLEZ GALLERO; CASABAN et ál., 2014: 169-178; CASABAN, 2017: 238-260).

Aparte de estos trabajos arqueológicos, el proyecto ForSEAdiscovery ha colaborado con otros proyectos en curso, como en la excavación de Delta III, en la bahía de Cádiz; en la excavación del Highbourne Cay wreck, un navío del siglo XVI en las Bahamas (OERTLING, 1989: 244-253; SMITH; KEITH; LAKEY, 1985: 63-72), y en los estudios sobre la expedición de Tristán de Luna, hundida en 1559, cuyos navíos fueron localizados en las costas de Pensacola (BENDING, 2018) ; aparte de la prospección llevada a cabo en los navíos sumergidos de la flota de Apodaca, en las costas de Trinidad y Tobago (CRESPO SOLANA; NAYLING 2016). En todos estos casos la misión del equipo de buceo del proyecto dirigido por Nigel Nayling ha sido siempre la recogida adecuada de muestras de madera.

\section{LA BASE DE DATOS FORSEADISCOVERY}

Como base para los estudios histórico-arqueológicos se están utilizando bases de datos, en algunos casos con datos geolocalizados, que han sido ya creadas en anteriores trabajos de investigación por parte de los miembros del Consorcio ${ }^{17}$. Estas bases de datos han experimentado un proceso de integración en un Sistema de Información Geográfica (SIG) que logra ofrecer una visualización cartográfica de la información. Precisamente, uno de los objetivos del proyecto era tanto la recogida de información cualitativa y cuantitativa de documentos y literatura como de bases de datos que aportan conocimientos valiosos sobre el comercio global de la madera que afectaba a la Península Ibérica. En este apartado contamos con la base de datos The Sound Toll Registers Online, que da mucha información sobre las exportaciones de madera a la Península Ibérica ${ }^{18}$. Pero es importante señalar que la base de datos y SIG ForSEAdiscovery integra importante información sobre las características de naufragios de buques ibéricos con el procesamiento de datos en bases de datos pre-existentes, principalmente la base de datos de The ShipLAB (TAMU A\&M) de Filipe Castro y la base de datos DynCoopNetData Collection (o CrespoDatabase Atlantic Trade) de la que escribe estas líneas. Estos datos están sirviendo aún para el cotejo de la información histórica y arqueológica sobre las características de construc-
16

SATCHELL, J.; RICH, S.; MOMBER, G. (FECHA) Yarmouth Roads Shipwreck Evaluation and Timber Sampling campaign: Assessing the local seabed archive to answer research questions of international importance. Documento de trabajo. Memoria de la intervención arqueológica realizada por Maritime Archaeology Tust, en el proyecto ForSEAdiscovery. Vease RICH, S. (2015) What's in a name? The Yarmouth Roads shipwreck and the Iberian connection <https://forseadiscovery. wordpress.com/whats-in-a-name-the-yarmouth-roads-shipwreck-and-the-iberian-connection/> [Consulta: 20/02/2019].

17

CRESPO SOLANA: http://digital.csic.es/handle/10261/28394 (Repositorio Digital CSIC); CASTRO: Early Modern Shipwrecks: http:// tamu.maps.arcgis.com/apps/MapJournal/ index.html? appid=da41bddb126241fea235ec934428d48c; NAYLING: http://archaeologydataservice.ac.uk/archives/view/newportship_2013/ (The Newport Ship); MOMBER: http://www.maritimearchaeologytrust.org/a2s (The Atlas of the Two Seas).

18

Esta base de datos: http://www.soundtoll.nl/ index.php/en/over-het-project/str-online está dirigida por el Dr. Jan Willem Veluwenkamp. 


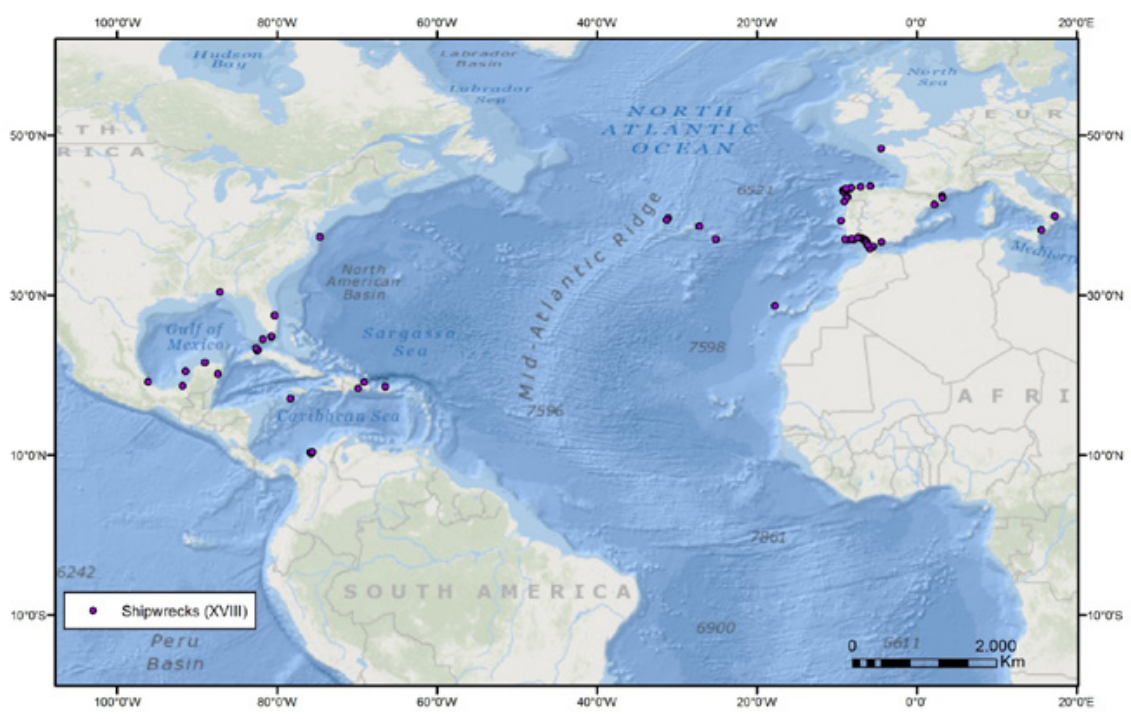

ForSEAdiscovery Database: Ejemplo de análisis sobre naufragios. Estadísticas

ción de los buques específicos en los astilleros del Atlántico ibérico y el uso de la madera contemporánea en un momento de importantes avances tecnológicos entre los siglos XVI y XVIII. La depuración y manejo de estos datos están sirviendo para poder cotejar esta información con la literatura precedente, a la que hice referencia en mi anterior estado de la cuestión, pero sin duda, y dada la enorme cantidad de información, será objeto de futuras investigaciones. Es el próximo objetivo la realización de una web mapping o visualizador que estará disponible online en el CSIC.

Para la elaboración de este SIG sobre historia y arqueología se ha realizado un trabajo muy minucioso durante cuatro años en el que han participado varios componentes del equipo del proyecto. Se ha desarrollado un modelo de datos orientado a SIG que combina la información de las diferentes disciplinas de historia, arqueología y técnicas de análisis de la madera. La base de datos ForSEAdiscovery no solo integra datos de las referidas bases de datos pre-existentes (cuyos datos han sido ya insertados convenientemente) sino que se ha visto enriquecida con una gran cantidad de datos procedentes de diversas fuentes de información: en primer lugar se trata de una investigación de base histórica básica que se ha llevado a cabo con la ingente documentación localizada en archivos españoles (especialmente Simancas, General de Indias de Sevilla) archivos holandeses y en Portugal. En este apartado se ha conseguido un catálogo de referencia básicamente sobre comercio atlántico que reúne identificación de navíos históricos (con datos históricos sobre cada barco) y navíos arqueológicos (con datos sobre pecios excavados y con información arqueológica. Además se ha obtenido una rica información en archivos y bibliotecas en relación con el comercio de madera y las rutas marítimas en los siglos de la Edad Moderna, así como la propia 


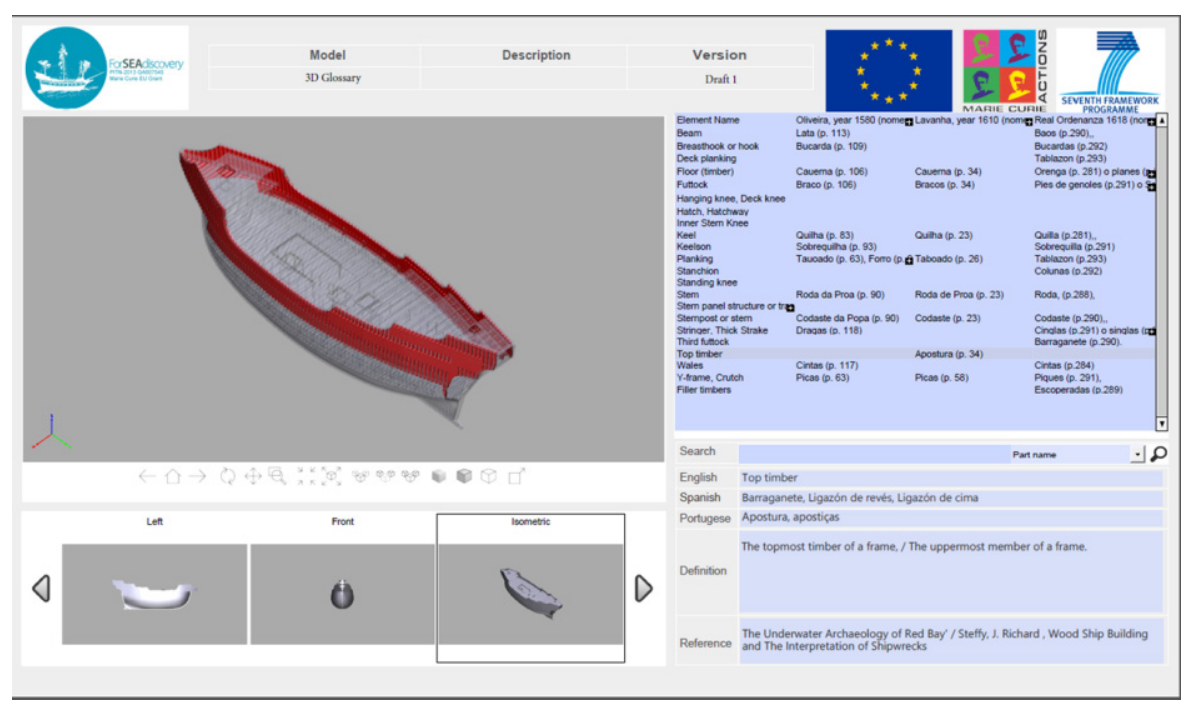

dinámica de las redes mercantiles (Merchant Networks) en esta economía de explotación forestal y de recursos. En relación con esta recopilación histórica se han llevado a cabo estudios complementarios históricos-arqueológicos sobre casos de uso concreto realizando intervenciones arqueológicas puntuales en pecios de la Edad Moderna, de construcción ibérica, previamente localizados en bases de datos. En estos pecios se ha procedido a la recogida de muestras de madera estructural con el fin de cotejarla con análisis dendrocronológicos y de procedencia de las maderas realizados en laboratorios. Estas muestras de madera se han obtenido en trabajo de campo con árboles vivos (Living trees) y en edificios históricos. Estos datos se están procesando para ser introducidos en el SIG, aunque hasta el momento se cuenta con, al menos, tres bases de datos intercalados con varias mapeos de barcos y naufragios.

El resultado de este SIG y base de datos ForSEAdiscovery integra así información de tres disciplinas diferentes, pero fuertemente relacionadas en lo que a datos se refiere. El modelo es la base para una plataforma GIS que puede además ser usada como herramienta de integración y de visualización para diferentes capas de información acerca de la localización geográfica de naufragios, objetos de estudio histórico-arqueológico y para ofrecer una adecuada narrativa al estudio de la navegación y su contexto. Su diseño está orientado a la identificación de comportamientos o modelos (patterns) en la evolución de la tecnología de construcción naval y del empleo de la madera y su procedencia. La base de datos está organizada en tablas, campos de atributos y relaciones entre tablas. Los resultados obtenidos ofrecen una visión muy amplia sobre cómo se llevaba a cabo, distribuía y monopolizaba el comercio de la madera entre España, Portugal y el norte de Europa
Tesauro de características de construcción naval. Referencia a maderas descritas en fuentes históricas y registros arqueológicos 
identificando las fuentes de recursos, el proceso de cómo se controlaba el talado de bosques, el transporte de la madera, la selección y las prácticas de organización de este comercio, así como la legislación que se produjo en torno a esto en los distintos países involucrados. En este marco se da vital importancia a las organizaciones y avatares de las flotas de Indias en sus viajes entre Europa y América con la intención de poder aglutinar información arqueológica, histórica y dendrocronológica de los navíos conocidos y localizados, aunque estos solo constituyen una pequeña parte en el estado actual de conocimientos (CRESPO SOLANA, 2018b). Se tiene la esperanza de poder avanzar en su conocimiento y protección y es un largo camino y trabajo por hacer en el que se necesita una cooperación de muchos especialistas y acceso a financiaciones internacionales, algo totalmente viable como el proyecto ForSEAdiscovery ha demostrado.

Relacionado con los trabajos de la base de datos se ha producido un glosario y una herramienta de representación 3D de los modelos de barcos teniendo en cuenta las piezas que lo componen y las especies utilizadas en su construcción. Este trabajo ha sido supervisado en la Universidad de Gales (UWTSD), por Nigel Nayling, como director de las campañas subacuáticas del proyecto.

\section{A MODO DE CONCLUSIÓN ¿UNA DENDROCRONOLOGÍA HISTÓRICA?}

La madera se convirtió en un recurso estratégico fundamental. Y ahora estamos conociendo más acerca de su explotación como recurso, su gestión, las políticas forestales y su evolución durante diversos períodos históricos, gracias también a los estudios realizados por ecólogos e ingenieros forestales. Como materia prima históricamente insostenible, la madera ha sido sometida a una gobernanza a partir de factores políticos y disponibilidad de recursos en cada tiempo histórico y ello ha influido en su explotación, pero también en la tecnología relacionada con su aplicabilidad, de acuerdo a la teoría de Jared Diamond sobre el materialismo cultural. Esto es algo que puede apreciarse en la evolución de la construcción naval. Ese materialismo cultural ayuda a entender en la historia las causas de las diferencias y similitudes socioculturales y la evolución en el proceso tecnológico. Aunque parezca increíble, en la historiografía española, la historia forestal, salvo honrosas excepciones, ha sido poco tratada desde el aspecto medioambiental. En el caso español sí se ha estudiado el siglo XVIII con una aproximación a dicha perspectiva, gracias a trabajos inolvidables como la Historia de un roble del siglo XVIII (ARANDA Y ANTÓN, 1990). A diferencia de este bien estudiado siglo, queda más por conocer de las épocas precedentes como ya algunos trabajos han señalado, en especial llevados a cabo durante este proyecto. La necesidad de los recursos del bosque es algo presente en el surgir de las ideas conservacionistas sobre la naturaleza a lo largo de los siglos y fue 
precisamente la politización de los problemas forestales por la "escasez de madera" la que dio lugar a la acumulación de conocimiento ecológico-forestal, siempre, especialmente durante los siglos XVII y XVIII, desde un punto de vista empírico-práctico.

Este proyecto aspira a integrar información sobre la procedencia de la madera con los datos históricos-arqueológicos. Tarea ardua dado que los conocimientos existentes se han centrado más parcialmente en la perspectiva histórica-tecnológica y menos en una consiliencia (consilience), en una disposición por unir conocimientos de distintas disciplinas para crear un marco unificado de entendimiento (VALBUENA-CARBAÑA; HEREDIA; FUENTES-UTRILLA et ál., 2010: 492-506; HALDONA; MORDECHAIA; TIMOTHY et ál., 2018: 3210-3218). Los análisis sobre la procedencia de la madera (Wood Provenance) no solo se aplican en restos extraídos en sitios sumergidos sino en las localizaciones de madera estructural o en conexión en zonas intermareales o costeras que puedan suponer un posible aporte a la elaboración de un catálogo de maderas históricas o de una dendrocronología histórica. Queda por hacer una adecuada dendrocronología de la Península Ibérica que nos dé datos de conexión entre la fragmentada información histórico-arqueológica que poseemos.

En el proyecto, los trabajos de muestreo en árboles vivos (Living Trees) y en edificios históricos han constituido un avance importante que aún está pendiente de producir datos en los laboratorios. Los avances recientes en la dendrocronología histórica, que permiten la datación junto a la creación de

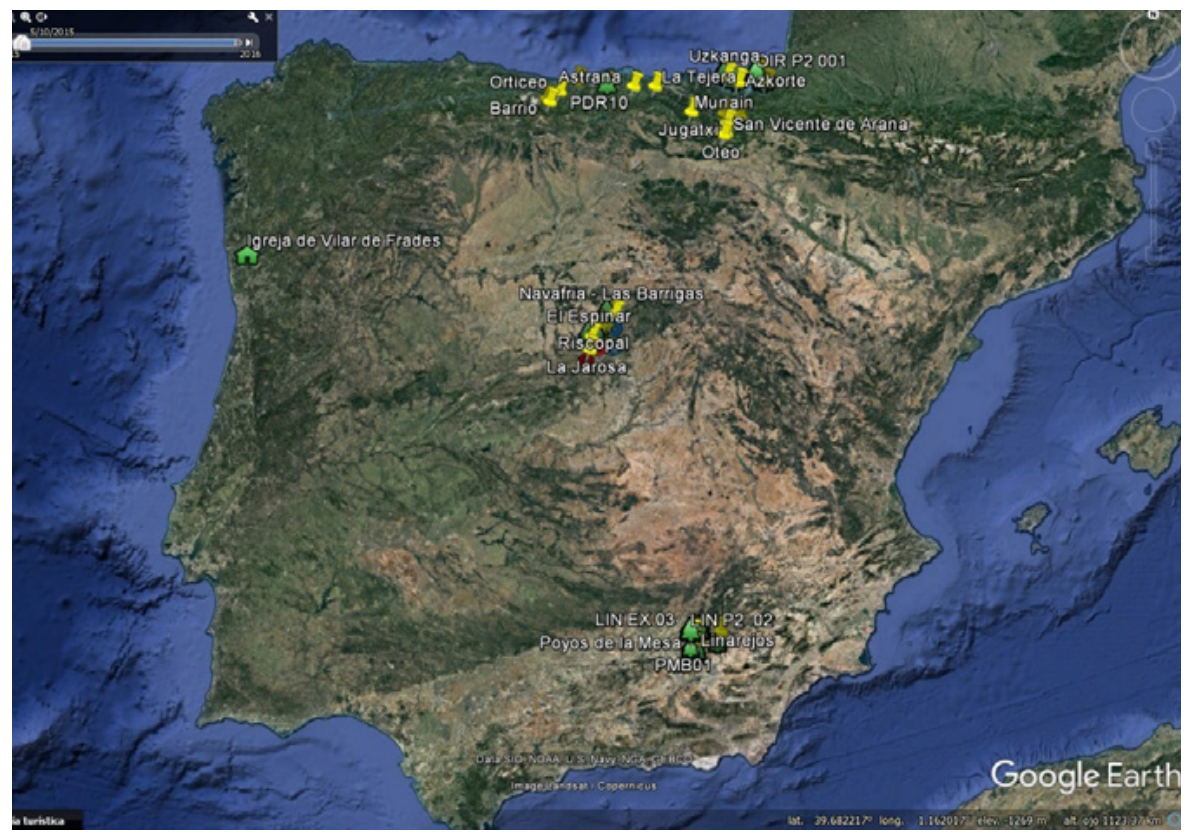


estas cronologías y los análisis químicos y de ADN relacionados, los cuales han experimentado mucho avance para algunas zonas de Europa (en Europa central y norte), están aún menos desarrollados en la Península Ibérica. Por lo tanto, el desarrollo de referencias cronológicas de anillos de árboles en zonas de la Península Ibérica que suministraban madera para la construcción naval, ampliado a otras zonas históricamente explotables como, aparte de la Cordillera Cantábrica, el Sistema Central, Cazorla o la Sierra de Segura, sería un primer paso para la evaluación de las fechas y procedencia de los recursos utilizados en la construcción naval en España y Portugal. Además, durante el proyecto se han implementado nuevos análisis que están dando lugar a técnicas emergentes como el análisis de isótopos estables (especialmente estroncio) y de ADN. La recogida de muestras ha tenido lugar en diversas zonas geográficas identificadas como "montes de marina" en la documentación histórica.

Ahora bien, dado el proceso de deforestación que ha sufrido la Península Ibérica, a veces es difícil localizar árboles vivos (de más de 300 o 400 años de antigüedad) que sirvan para datar madera de un galeón del siglo XVI o XVII. Los escasos especímenes de mayor edad están localizados y protegidos por el ministerio español de Medioambiente, al igual que también sucede para el caso de Portugal. Por ello, se ha realizado un importante y paralelo muestreo de madera en edificios históricos. En este apartado la dendrocronología histórica ha servido para poder datar madera antigua que se encuentra en la importante arquitectura del patrimonio español y portugués, como ha sucedido, por ejemplo, con las catedrales de Segovia y Jaén, que han sido útiles para la datación de pecios (DOMÍNGUEZ-DELMÁS; ALEJANO-MONGE; DAALEN at ál., 2015; DOMÍNGUEZ-DELMÁS; ALEJANO-MONGE; WAZNY at ál., 2013: 635-652).

En definitiva, el análisis dendrocronológico sobre la procedencia de la madera que se utilizó para la construcción naval requiere un nuevo enfoque integrado: se ha estado complementando la información de las fuentes históricas con un estudio de los anillos de los árboles, su anatomía y su ADN. Esta información se encuentra en las bases de datos dendrocronológicas. Ello está permitiendo realizar una identificación fiable de madera, así como para caracterizar las áreas de origen de la madera en la Península Ibérica y diferenciar qué madera se usó de origen local de la importada, sobre todo de área Scando-Báltica. A su vez, se han realizado estudios que comparan muestras de árboles vivos con la madera que se proporcionaba a los astilleros o que se suministraban para la construcción de edificios históricos, y que venían de diversos lugares. Las muestras de maderas de pecios, recogidas durante las campañas de arqueología subacuática, previamente identificados se utilizan también como material de prueba para hacer verificaciones sobre el origen de la madera. La importancia de este análisis radica en el cotejo comparado (Data-crossing) con la información histórica existente. 
Tanto la recogida de muestras de madera llevada a cabo por los dendrocronólogos (de árboles vivos) como por los arqueólogos marítimos (muestras de madera de los pecios) es fundamental con objeto de cotejar ambos resultados y dejar lo más claro posible la identificación de la procedencia de la madera que fue utilizada en la construcción de un determinado barco. Gracias a ello se podrá averiguar si los datos químicos coinciden con la información que proporciona la información histórica. Aunque la diferenciación de las especies de robles y pinos es directa por la observación de los árboles vivos, esto no se ha logrado con éxito para el estudio de la anatomía de la madera. Y ello es crucial para determinar si un barco se construyó en un astillero de la Península Ibérica o en otro lugar. El roble y la madera de pino se importaron a España y a Portugal en la Edad Moderna, pero la madera ibérica no se exportó a otra parte para uso en los astilleros. Quercus Faginea y Quercus Pyrenaica son endémicas de la Península Ibérica y se encuentran en grandes cantidades como maderas estructurales originales en un barco. Esto podría ser una indicación a la hora de determinar si un barco fue construido en un astillero de la Península Ibérica. Esto es básicamente nuestro reto futuro en la investigación interdisciplinar. 


\section{BIBLIOGRAFÍA}

- ALCALÁ-ZAMORA Y QUEIPO DE LLANO, J. (2001) España, Flandes y el Mar del Norte (1618-1639). La última ofensiva europea de los Austrias madrileños. Madrid: Centro de Estudios Políticos y constitucionales, 2001

- ARANDA Y ANTÓN, G. (1990) Los bosques flotantes. Historia de un roble del siglo XVIII. Madrid: Icona, 1990

- BAUDOT MONROY, M. (2012) Barcos para el rey: Juan de Arroaga, la madera y la construcción naval (1752-1759). En GARCÍA HURTADO, M. (coord.) La Armada española en el siglo XVIII: ciencia, hombres y barcos, 2012, pp. 297328

- BENDING, CH. (2018) Amidships Assembly of the Sixteenth-Century Emanuel Point II Shipwreck. International Journal of Historical Archaeology. https://doi.org/10.1007/ s10761-018-0477-y

- CASTRO, F. V. (DE) (2005) The Pepper Wreck: A Portuguese Indiaman at the Mouth of the Tagus River. Texas: Ed. Rachal Foundation Nautical Archaeology Series, 2005

- CASTRO, F.; YAMAFUNE, K.; EGINTON, C. DERRYBERRY, T. (2011) The Cais do Sodré Shipwreck. International Journal of Nautical Archaeology, 40- 2, 2011, pp. 328-34

- CASABAN, J. L. (2017) Santiago de Galicia and the Illyrian squadron: Characteristics, dimensions and tonnages of Mediterranean-built galleons for Philip's II Atlantic fleets (1593-1597). The International Journal of Maritime History, vol. 29(2), 2017, pp. 238- 260

- CASADO SOTO, J. L. (2009) La construcción naval hispana en época moderna. En CAU ONTIVEROS, M. A.; NIETO PRIETO, X. (coords.) Arqueologia nàutica mediterràni. Girona: Centre d'Arqueologia Subacuàtica de Catalunya, 2009, pp. 393-410

- CASADO SOTO, J. L. (2003) La invención del galeón oceánico de guerra español. RIBOT GARCIA, L.; DA ROSA, L. (coord.) Naves, puertos e itinerarios marítimos en la época moderna. Madrid: Editorial Actas, 2003, pp. 37-70

- CRESPO SOlANA, A.; NAYLING, N.; GARCÍAGONZÁLEZ, I. (2014-2018) ForSEAdiscovery. Forest Resources for Iberian Empires: Ecology and Globalization in the Age of Discovery (XVI-XVIII centuries). Madrid: Consejo Superior de Investigaciones Científicas, 20142018. DOI: http://dx.doi.org/10.20350/digitalCSIC/8587

- CAZENAVE dE LA ROCHE, A. (2018) La construction navale au XVlème siècle en Méditerranée: l'apport de l'épave de la Mortella III (Saint-Florent, Haute-Corse). Tesis doctoral Université de Paris-Sorbonne, 2018

- CRESPO SOlANA, A. (2018a) Dutch Trade and Spatial Integration between the Baltic and Spain, 1700-1778. En VELUWENKAMP, J. W.; SCHELTJENS, W. (ed.) Early
Modern Shipping and Trade Novel Approaches Using Sound Toll Registers Online. Leiden: Brill, 2018, pp. 77-94

- CRESPO SOlANA, A. (2018b) La organización de las flotas hispano-caribeñas y su logística (1717-1746). Una aproximación desde la Arqueología náutica. En GRAFENSTEIN, J. VON; REICHERT, R.; RODRÍGUEZ TREVIÑO, J. C. (coord.) Entre lo legal, lo ilícito y lo clandestino. Prácticas comerciales y navegación en el Gran Caribe, siglos XVII al XIX. México: Conacyt, 2018

- CRESPO SOLANA, A. (2017) Merchants and the beating of a butterfly's wings: from local to global in the transfer of economic behavior models in the 18th century. En HERRERO SÁNCHEZ, M.; KAMPS, K. (ed.) Merchants and Trade Networks in the Atlantic and the Mediterranean, 1550-1800: Connectors of Commercial Maritime Systems. London: Pickering \& Chatto Publishers LTD, 2017, pp. 83105

- CRESPO SOlANA, A. (2016) Wood Resources, shipbuilding and Social Environment: The Historical context of the ForSEAdiscovery Project. Skyllis. Journal of the German Society for the Promotion of Underwater Archaeology, 15, n. ${ }^{\circ}$ 1, 2015

- CRESPO SOlANA, A. (2014) Spatio-Temporal Narratives: Historical GIS and the study of Global Trading networks (1500- 1800). Cambridge Scholar Publishing, 2014

- CRESPOSOLANA,A. (2013)LaHistoriageográficamente integrada y los Sistemas de InformaciónGeográfica (SIG): concepto y retos metodológicos. Tiempos Modernos, 26/ 1 (Monográfico Historia moderna y Sistemas de Información Geográfica, coordinado por David Alonso)

- CRESPO SOlANA, A. (2009) Mercaderes Atlánticos. Redes del comercio flamenco y holandés entre Europa y el Caribe. Córdoba: Editorial, 2009

- CRESPO SOlANA, A. (2001) El comercio marítimo entre Cádiz y Amsterdam, 1713-1778. Madrid: Banco de España, 2001

- CRESPO SOlANA, A. (1996) La Casa de la Contratación y la Intendencia General de la Marina en Cádiz, 1717-1730. Cádiz: Servicio de Publicaciones Universidad de Cádiz. 1996

- CREspo solanA, A; CASTRO, F. (2016) The ForSEAdiscovery database. The origin <https://www. academia.edu/20167289/The_ForSEAdiscovery_ Database._The_origin> [Consulta: $20 / 03 / 2019]$

- CRESPO SOlANA, A.; NAYLING, N. (2016) Archaeohistorical and dendrochronological study of the wrecks of the fleet of Apodaca. ForSEAdiscovery Project, Report (literatura gris)

- DOMínguEZ-DELMÁS, M.; ALEJANO-MONGE, R.; 
DAALEN, S. VAN; RODÍGUEZ-TROBAJO, E.; GARCÍAGONZÁLEZ, I.; SUSPÉRREGUI, J.; WAZNY, TH.; JANSMA, E. (2015) Tree-rings, forest history and cultural heritage: current state and future prospects of dendroarchaeology in the Iberian Peninsula. Journal of Archaeological Science, 2015, pp. $180-196$

- DOMÍNGUEZ-DELMÁS, M.; ALEJANO-MONGE, R.; WAZNY, TH.; GARCÍA GONZÁLEZ, I. (2013) Radial growth variations of black pine along an elevation gradient in the Cazorla Mountains (South of Spain) and their relevance for historical and environmental studies. European Journal of Forest Research, 132, 2013, pp. 635-652

- DÓMÍNGUEZ-DELMÁS, M.; NAYLING, N.; LOUREIRO, V.; LAVIER, J. (2012) Dendrochronological Dating and Provenancing of Timbers from the Arade 1 Shipwreck, Portugal. The International Journal of Nautical Archaeology 42.1, pp. $118-136$

- DOMÍNGUEZ-DELMÁS, M.; RICH, S.; DALY, A.; NAYLING, N.; HANECA, K. (2018) Selecting and Sampling Shipwreck Timbers for Dendrochronological Research: practical guidance. The International Journal of Nautical Archaeology, 0.0, 2018, pp. 1-14

- DOMÍNGUEZ-DELMÁS, M. (2015) Forest History, Timber supply and Tree Rings. A dendroarchaeological approach to the study of Iberian cultural heritage. Tesis doctoral inédita. Universidad de Huelva, 2015

- DOMíngueZ-DELMÁs, M. (2013) Avances de la dendrocronología al servicio de la Arqueología subacuática española, ¿Qué información podemos extraer de la madera de los pecios? En NIETO PRIETO, X.; RAMÍREZ PERNÍA, A.; RECIO SÁNCHEZ, P. (coord.) Actas del I Congreso de Arqueología Naútica y Subacuática Española, Cartagena, 14, 15 y 16 de marzo de 2013, pp. 1080-1094

- EGUILUZ MIRANDA, B.; TRAPAGA MONCHET, K.; DOMÍNGUEZ-DELMÁS, M.; SAN CLAUDIO SANTA CRUZ, M.; GASCH-TOMÁS, J. L.; CRESPO SOLANA, A.; NAYLING, N. (2015) The Ribadeo shipwreck (c.1600): can we identify the ship through a multidisciplinary approach? En Actas del VI Congreso Internacional de Arqueología Subacuática (IKUWA VI), del 28 de noviembre al 2 de diciembre de 2015, Fremantle, Australia (en prensa)

- FUENTE DE PABLO, P. (DE LA) (2006) El Triunfante: tecnología y ciencia en la España de la llustración. Barcelona: Museo Marítimo, 2006

- GALLAGHER, N. (2016) A methodology for estimating the volume of Baltic timber to Spain using the Sound Toll Registers: 1670-1806. The International Journal of Maritime History, Vol. 28(4), 2016, pp. 752-773

- garcía RIVERA, C.; MARTí SOlANO, J.; ALONSO VILLALOBOS, C.; GALLARDO ABÁRZUZA, M. (1995) Carta arqueológica Subacuática de la Bahía de Cádiz.
Cuadernos de arqueología marítima, n. ${ }^{\circ} 3,1995$, pp. 105124

- gASCH-TOMAS, J. L.; TRAPAGA MONCHET, K.; TRINDADE, A. R. (2017) Shipbuilding in times of war: Contracts for the construction of ships and provision of supplies in the Spanish Empire in the early seventeenth century. The International Journal of Maritime History, vol. 29(1), pp. 187-92

- GUIMERÁ, A.; CHALINE, O. (2018) (dir.) La Real Armada. La Marine des Bourbons d'Espagne au XVIIle siécle. Paris-Sorbonne: PUPS, 2018

- HAJ, F. (2017) Utilisation des isotopes stables et radiogéniques du stron@um pour tracer la provenance des bois: application à des épaves sous-marines. Tesis doctoral defendida el 14 de noviembre 2017 en Nancy, Universidad de Lorraine (Francia)

- HALDONA, J.; MORDECHAIA, L.; TIMOTHY, P.; NEWFIELB, C.; CHASED, A. F.; IZDEBSKIE, A.; GUZOWSKIG, P.; LABUHNH, I.; ROBERTSI, N. (2018) History meets palaeoscience: Consilience and collaboration in studying past societal responses to environmental change. PNAS, marzo 27, vol. 115/3, 2018, pp. 3210-3218

- HORMAECHEA, C.; RIVERA, I.; DERQUI, M. (2012) Los galeones españoles del siglo XVII. 2 tomos. Barcelona: Museu Marítim de Barcelona, 2012

- JIMÉNEZ MONTES, G. (2016) Las redes comerciales del norte de Europa en el suministro de madera a Andalucía de 1581 a 1621. GARCÍA FERNÁNDEZ, M. (ed.) (2016) Familia, cultura material y formas de poder en la España moderna. Madrid: FEHM, 2016, pp. 693-702

- KUMAR, M. (2018a) A method for estimating the volume of the Baltic timber products exported through the Sound and its application to Portugal, 1669-1815. Scandinavian Economic History Review, 2018, pp. 1-19

- KUMAR, M. (2018b) In defence of Bang and Korst's Sound Toll Tables. International Journal of Maritime History, 2018, pp. 1-6

- LEON AMORES, C. (2009) Buceando en el pasado. Los grandes naufragios de la Historia. Madrid: Espasa, 2009, pp. 178 y ss.

- Novisima recopilación de las LEYES de España: dividida en XII libros. (1805-1829) Volumen 6, Madrid:, [s.n.], 18051829, pp. 193-194

- LOEWEN, B. (1998) The Red Bay vessel. An example of a Sixteenth century Biscayan ship. Itsas Memoria. Revistas de Estudios Marítimos del País Vasco, 2. Donostia, San Sebastián: Untzi Museoa- Museo Naval, 1998, pp. 193-199;

- LÓPEZ ARANDIA, A. (2018) Aprovisionando de madera el arsenal de Cartagena: el proyecto de Manuel Bernia y 
las flotaciones por el río Segura (1784-1793). Tiempos Modernos, 36 (2018/1), pp. 127-168

- MARTí SOLANO, J. (2014) Actuaciones en Andalucía en desarrollo del Plan Nacional de Arqueología subacuática. En NIETO PRIETO, F. X.; BETHENCOURT, M. (coord.) Arqueología subacuática española: Actas del I Congreso de Arqueología Naútica y Subacuática Española, vol. 2, 2014, pp. 109-118

- MARTÍNEZ GONZÁLEZ,A. J. (2015) La superintendencia de montes y plantíos (1574-1748). Valencia: Ed. Tirant Lo Blanch, 2015

- MARTÍNEZ LILLO, S.; BLANQUEZ, J. (ed.) (1993) II Curso de Arqueología subacuática. Madrid, 1993, pp. 163169

- MIRA CABALlOS, E. (2005) Las Armadas imperiales. La guerra en el mar en tiempos de Carlos $V$ y Felipe II. Madrid: Ed. La esfera de los libros, 2005

- NAYLING, N. (2008) The application of dendrochronology to underwater archaeology. En TSANG, C. (ed.) International Symposium on Underwater Archaeology. Taiwan: 2008, pp. 64-73

- NAYLING, N.; JONES, T. (2014) The Newport Medieval ship, Wales, United Kingdom. The International Journal of Nautical Archaeology, vol. 43, 2, pp. 239-278

- NAYLING, N.; SUSPÉRREGUI, J. (2014) Iberian Dendrochronology and the Newport Medieval ship. The International Journal of Nautical Archaeology, vol. 43, 2, pp. $279-291$

- OERTLING, T. J. (1989) The Highborn Cay Wreck: The 1986 Field Season. International Journal of Nautical Archaeology, 18 (3), pp. 244-253

- PÉREZ- MALlainA BUENO, P. E. (2015) Naufragios en la Carrera de Indias durante los siglos XVI y XVII. El hombre frente al mar. Sevilla: Universidad de Sevilla, 2015

- PUJOL I HAMELINK, M.; VIVAR I LOMBARTE, G.; FUENTE DE PABLO, P. (2011) El navío Triunfante: Jorge Juan y la construcción a la inglesa. En AA. VV. Actas de las Jornadas de ARQUA 2011. Cartagena, 3 y 4 de diciembre de 2011. Ministerio de Educación, Cultura y Deporte, 2011

- QUINTERO GONZÁlEZ, J. (2004a) Las gentes de la maestranza y los reclusos del arsenal de La Carraca en el siglo XVIII. Revista de historia naval, año n. ${ }^{\circ} 22, n .{ }^{\circ} 84$, 2004, pp. 27-40

- QUINTERO GONZÁLEZ, J. (2004b) La arboladura en la construcción naval del siglo XVIII. Revista de historia naval, año $n^{\circ} 22$, n. ${ }^{\circ} 87,2004$, pp. 81-94

- QUINTERO GONZÁLEZ, J. (2004c) La madera en los pertrechos navales: Provisión de motones, remos y bombas al arsenal de La Carraca. Tiempos modernos: Revista Electrónica de Historia Moderna, vol. 4, n. ${ }^{\circ}$ 10, 2004

- RAHN PHILIPS, C. (2013) Guerra en el mar. Tecnología y armamento en el Mundo Atlántico. En O'DONNELL Y DUQUE DE ESTRADA, H. (coord.) Historia Militar de España. Edad Moderna, vol. I (Ultramar y la Marina). Comisión Española de Historia Militar, Real Academia de la Historia, Ministerio de Defensa, 2013, pp. 254-269

- REICHERT, R. (2016) El comercio directo de maderas para la construcción naval española y de otros bienes provenientes de la región del Báltico sur, 1700-1783. Hispania, 76, 252, pp. 129-157

- RICH, S.; NAYLING, N.; MOMBER, G.; CRESPO SOLANA, A. (2017) Shipwrecks and Provenance. In Situ timber sampling protocols with a focus on wrecks of the Iberian shipbuilding tradition. Archaeopress Publishing Ltd., 2017

- RIDELLA, R. G.; ALZAGA, M.; ENRÍQUEZ MARCÍAS, G.; GALLARDO ABÁRZUZA, M.; HIGUERAS MILENA, J. M.; CIACCHELA, F. (2017) The Cadiz-Delta II wreck: the "San Giorgio" a Genoese merchantman sunk by Francis Drake in 1587. Archeologia Post Medievale. Società, Ambiente, Produzione, 20, 2017, pp. 11-65

- TRINDADE, A., DOMÍNGUEZ-DELMÁS, M. TRAORE, M., GALLAGHER, N., RICH, S. MARTINS, A. (2015) From Forests to the Sea, from the Sea to the Laboratory: the Timbers of the Frigate Santa Maria Magdalena (18th century). En Actas del VI Congreso Internacional de Arqueología Subacuática (IKUWA VI), del 28 de noviembre al 2 de diciembre de 2015, Fremantle, Australia (en prensa)

- RODRígueZ TROBAJO, E. (2008) Procedencia y uso de madera de pino silvestre y pino laricio en edificios históricos de Castilla y Andalucía. Arqueología de la Arquitectura, pp. 33-53

- SAN CLAUDIO, M. (2017) El Atlántico norte español, un espacio estratégico para un imperio. Siglo XVI: una visión arqueológica. Tesis doctoral inédita. Universidad de Zaragoza

- san ClaUdio SANTA CRUZ, M.; GONZÁlez GALLERO, R.; CASABAN, J. L.; CASTRO, F. (2014) El precio de Ribadeo, un excepcionalmente bien conservado pecio español del siglo XVI. En NIETO PRIETO, F. X.; BETHENCOURT, M.(coord.) Arqueología subacuática española: Actas del I Congreso de Arqueología Naútica y Subacuática Española, vol. 1, 2014, pp. 169-178; pp. 221227

- SERRANO MANGAS, F. (1989) Armadas y flotas de la plata (1620-1648). Madrid: Banco de España, 1989

- SMITH, R. G.; KEITH, D. H.; LAKEY, D. (1985) The Highborn Cay Wreck: Further Exploration of a 16th-Century 
Bahaman Shipwreck. International Journal of Nautical Archaeology, 14 (1), 1985, pp. 63-72

- SOBERÓN, M.; PUJOL, M.; LLERGO, Y.; RIERA, S.; JULIÁ, R.; DOMÍNGUEZ, M. (2012) El Barceloneta I. Una embarcación medieval a tingladillo en Barcelona. ITSAS. Memoria. Revistas de Estudios Marítimos, 7, Untzi MuseoaMuseo Naval, Donostia-San Sebastián, 2012, pp. 411-422

- TORRES SÁNCHEZ, R. (2013) Administración o asiento. La política estatal de suministros militares en la Monarquía Española del siglo XVIII. Studia Historica, 35, pp. 159-199

- TRAORÉ, M. (2018) Potential Biomarkers of provenance of the wood from Iberian Typology shipwrecks $\left(15^{\text {th }}-17^{\text {th }}\right.$ centuries). Tésis doctoral inédita. Universidad de Santiago de Compostela, 2018

- TRAPAgA MONCHET, K.; SANTOS, A. (2015) Forestry and timber supply in the Royal Forests of the Iberian Peninsula through the $16^{\text {th }}$ century. Skyllis, 1, 2015, pp. 6268

- TRINDADE, A. R. (2015) Bourbon Naval Policy, Forestry and Timber Supply for Shipbuilding inAndalucia (1700-1759): Brief introductory research notes. En VARELA GOMES, R.; VARELA GOMES, M. (coord.) The management of Iberian Forest Resources in the Early Modern Shipbuilding: History and Archaeology. Lisboa: IAP, 2015, pp. 57-65

- TRINDADE, A.; DOMÍNGUEZ-DELMÁS, M.; TRAORE, M.; GALLAGHER, N.; RICH, S.; MARTINS, A. (en prensa) From forests to the sea, from the sea to the laboratory: the Santa Maria Magdalena frigate. En Actas del VI Congreso Internacional de Arqueología Subacuática (IKUWA VI), del 28 de noviembre al 2 de diciembre de 2015, Fremantle, Australia (en prensa)

- UZTÁRIZ, J. (DE) (1724) Theorica y practica del comercio y marina. Madrid: s.n., 1724, cap. LXIII, p. 162

- VALBUENA-CARBAÑA, M.; HEREDIA, U.; FUENTESUTRILLA, P.; GONZÁLEZ-DONCEL, I. G. (2010) Historical and recent changes in the Spanish forests: A socio-economic process. Review of Palaeobotany and Palynology, 162, 2010, pp. 492-506

- VALDEZ-BUBNOV, I. (2018) Shipbuilding administration under the Spanish Habsburg and Bourbon regimes (15901834): A comparative perspective. Business History, 60:1, 2018, pp. $105-125$

- VARELA GOMES, R.; TRAPAGA MONCHET, K. (ed.) (2017) Árvores, barcos e homens na Península Ibérica (Séculos XVI-XVIII). Lisboa: IAP, 2017

- VIVAR loMbarte, G.; Geli, R.; NIETO PRIETO, X.; DELTEBRE I. (2014) Un barco hundido en la desembocadura del Ebro durante la guerra del francés. En NIETO PRIETO, F. X.; BETHENCOURT, M. Arqueología subacuática, vol. 1, 2014, pp. 221-227
- WATSON, K.; GALE, A. (1990) Site evaluation for marine sites and monuments records: the Yarmouth Roads Wreck investigations. International Journal of Nautical Archaeology, 19.3, 1990, pp.183-192 